\title{
Is male infertility associated with increased oxidative stress in seminal plasma? A-meta analysis
}

\author{
Chao Huang ${ }^{1,2, *}$, Xiyue Cao ${ }^{1,2, *}$, Dejiang Pang ${ }^{3, *}$, Chao Li, ${ }^{1,2}$, Qihui Luo ${ }^{1,2}$, Yuanfeng \\ $\mathrm{Zou}^{2}$, Bin Feng ${ }^{4}$, Lixia $\mathrm{Li}^{2}$, Anchun Cheng ${ }^{1,2}$ and Zhengli Chen ${ }^{1,2}$ \\ ${ }^{1}$ Laboratory of Experimental Animal Disease Model, College of Veterinary Medicine, Sichuan Agricultural University, Chengdu \\ 611130, China \\ ${ }^{2}$ Key Laboratory of Animal Disease and Human Health of Sichuan Province, College of Veterinary Medicine, Sichuan \\ Agricultural University, Chengdu 611130, China \\ ${ }^{3}$ Department of Biochemistry and Molecular Biology, West China School of Preclinical and Forensic Medicine, West China \\ Hospital, Sichuan University, Chengdu 610041, China \\ ${ }^{4}$ Animal Nutrition Institute, Sichuan Agricultural University, Chengdu 611130, China \\ *These authors contributed to the work equally \\ Correspondence to: Zhengli Chen, email: chzhli75@163.com
}

Keywords: oxidative stress; antioxidants; male infertility; meta-analysis; markers

Received: June 22, $2017 \quad$ Accepted: March 22, $2018 \quad$ Published: May 11, 2018

Copyright: Huang et al. This is an open-access article distributed under the terms of the Creative Commons Attribution License 3.0 (CC BY 3.0), which permits unrestricted use, distribution, and reproduction in any medium, provided the original author and source are credited.

\section{ABSTRACT}

Objectives: We conducted a systematic review and meta-analysis of observational case-control studies to evaluate markers of oxidative stress in seminal plasma of patients with male infertility.

Background: Current evidence links oxidative stress to male infertility, in which multiple markers of oxidative stress have been widely detected, publishing inconsistent results with regard to the role of oxidative stress markers in the evaluation of male infertility. Therefore, a systematic review and meta-analysis on this issue is necessary.

Results: From the 1024 articles initially retrieved, 65 studies were included in our meta-analysis with 11 oxidative stress markers, containing $\mathbf{3 8 1 9}$ male infertility patients and 2012 controls. The concentrations of malondialdehyde (SMD $=1.86, p<$ $0.00001)$, NO $(S M D=0.89, p=0.001)$, carbonyl protein $(S M D=2.09, p<0.00001)$ in seminal plasma were significantly higher in infertility patients. The concentrations of GSH (SMD $=-1.68, p<0.00001)$, vitamin C (SMD $=-1.12, p<0.00001)$, and vitamin E (SMD $=-1.48, p=0.003)$, as well as the activities of catalase (SMD $=-1.91, p$ $<0.0001)$, glutathione peroxidase (SMD $=-1.96, p=0.0002)$ and glutathione-Stransferase (SMD $=-1.62, p=0.009$ ) declined remarkably, resulting in decreased total antioxidant capacity (SMD $=-1.77, p<0.00001$ ). Besides, the activity of superoxide dismutase showed no statistical difference between infertility patients and controls (SMD $=-0.51, p=0.07$ ).

Conclusions: Our meta-analysis suggests that oxidative stress in seminal plasma resulting from decreased antioxidant defense are associated with male infertility.

Methods: Using PubMed, EMBASE, CNKI, VIP, and Wanfang database, we searched for literature reporting the detection of oxidative stress markers in the seminal plasma of male infertility published up to June 2017. Standardized mean differences (SMDs) and $95 \%$ confidence intervals $(95 \% \mathrm{CI})$ were calculated for the finally analysis. 


\section{INTRODUCTION}

Infertility has become an increasing medical problem affecting approximately $15 \%$ of couples worldwide, of which male factors account for almost $50 \%$ cases [1]. Male infertility is common due to deficiencies in the semen, so seminal analysis is a keystone for the assessment of male fertilization potential, according to which the semen deficiencies are often labeled as oligozoospermia, aspermia, hypospermia, azoospermia, teratospermia, asthenozoospermia, or even combinations of these [2]. Genetic problems, immunologic disorders, obstructive lesions, varicocele, cryptorchidism etc. are frequently involved in male infertility, but the exact mechanisms of many cases are not well known, making the therapy face lots of challenges [3-5]. As a result, growing interests are elicited in identifying more causes of male infertility.

In recent decades, extensive researches have reported an important role of oxidative stress in causing male infertility, suggesting that the pathology of infertility in $30-80 \%$ of infertile men is oxidative damage to spermatozoa [6-10]. Oxidative stress happens as a result of the excessively reactive oxygen species (ROS) or reactive nitrogen species (RNS) accumulation, due to either increased ROS/RNS generation or impaired ROS/RNS clearance. It will cause extensive sperm DNA damage [11], reduced sperm motility [12], decline in sperm fertilising ability [13], and defective sperm membrane integrity via lipid peroxidation [14], all of which are important mechanisms behind sperm dysfunction. The major sources of ROS/RNS in semen include activated leukocytes in the seminal plasma and the mitochondria in the spermatozoa, while leukocytes in seminal plasma produce 1,000 times more ROS/RNS than the spermatozoa does [15].

To counteract the effects of ROS/RNS, semen is proved to possess a large amount of antioxidants, thereby protecting gonadal cells and mature spermatozoa from oxidative damage, especially after leaving the testicles. The antioxidants in semen are present both in spermatozoa and seminal plasma, but most abundant in seminal plasma, because the amount of spermatozoa cytoplasm is low, making the antioxidant defense activity limited [16]. Seminal plasma is enriched with both enzymatic antioxidants, such as superoxide dismutase (SOD), catalase, glutathione peroxidase (GPX), glutathione S-transferase (GST), and non-enzymatic antioxidants such as glutathione, vitamin $\mathrm{A}$, vitamin $\mathrm{C}$, vitamin $\mathrm{E}$, coenzyme Q10 etc. [17]. Deficiencies of enzymatic or non-enzymatic antioxidant systems in seminal plasma are widely associated with male infertility as the absence of any of these systems leads to the accumulation of excessive levels of ROS, resulting in impairment of both the structural and functional integrity of spermatozoa
$[18,19]$. However, previous studies addressing the oxidative stress status or detecting the markers of oxidative stress in seminal plasma of male infertile patients yielded controversial results, possibly due to the relatively small sample sizes of most of these studies, the different regions where the subjects were from, and the variability in the markers and assays used in them. In order to overcome these limitations, we conducted a systematic review and meta-analysis, and sought to rigorously evaluate current evidence from a large number of studies addressing the differences in markers of oxidative stress (MDA, TAC, SOD, Catalase, GPX, GST, Ve, Vc, NO, GSH and protein carbonyl) in seminal plasma between male infertile patients and controls.

\section{METHODS}

This systematic review and meta-analysis was performed according to the preferred reporting items for systematic reviews and meta-analyses.

\section{Search strategies}

A systematic review of the literature was conducted using PubMed, EMBASE, Chinese National Knowledge Infrastructure (CNKI), VIP information database, and Wanfang database. Studies reporting biomarkers of oxidative stress in the seminal plasma of infertile patients and controls published up to June 2017 were identified and analyzed. In addition, a hand search of the references of the retrieved articles and relevant reviews was performed to identify other potentially eligible studies. The following search strategy was used for PubMed, and was modified to suit other databases to include potentially relevant reports. Disagreements were resolved by discussion or consensus of a fourth reviewer (Z.C.).

1. infertility/ or infertile/ or subfertile/ or subfertility/ or sterility

2. oxidative stress/ or antioxidant/ or reactive oxygen species/ or reactive nitrogen species/ or free radicals/ or nitric oxide

3. total antioxidant capacity/ or total antioxidant power/ or total oxidant status/ or total antioxidant status

4. oxidative damages/ or protein carbonyl/ or protein carbonylation/ or lipid peroxidation/ or malondialdehyde/ or 8-hydroxydeoxyguanosine/ or thiobarbituric acid reactive substances/ or asymmetric dimethylarginine

5. xanthine oxidase/ or superoxide dismutase/ or glutathione/ or glutathione peroxidase/ or glutathione transferase/ or catalase

6. homocysteine/ or vitamin $\mathrm{A} /$ or vitamin $\mathrm{C} /$ or vitamin $\mathrm{E} /$ or coenzyme Q10

7. 1 and 2 or 3-6 


\section{Inclusion and exclusion criteria}

Inclusion criteria included: 1) studies where oxidative stress biomarkers were detected in the seminal plasma of infertile patients and fertile controls; 2) the mean and standard deviation of the levels of oxidative stress markers could be obtained or calculated using the data provided therein;

Exclusion criteria included: 1) case reports, abstracts, reviews, or irrelevant to the current analysis; 2) animal studies and female infertility; 3) studies of infertile patients with testicular varicocele, leukocytospermia, infection, or on antioxidant supplement; 4) studies only reporting oxidative stress markers in non-seminal plasma; 5) studies with no control groups; 6) studies with data only in graphic form; 7) duplicate publications or studies with inappropriate outcome measure.

\section{Data extract}

Two reviewers (C. H. and X.C.) independently performed data extraction using a standard data extraction form to determine eligibility for inclusion and data extract. Data was extracted for meta-analysis only when the markers were studied in three or more reports. The study with the largest sample size was included in the meta-analysis to avoid over-representation of cases when the same author had published two or more articles using the same or similar data within five years; otherwise, the latest study was included. The extracted data elements of this review included: 1) publication details: first author's last name, publication year, and country of the studied population; (2) study design; (3) characteristics of the studied population: sample size, age; (4) the mean and standard deviation of the oxidative stress markers. Disagreements were resolved by discussion or consensus with a third reviewer (Z.C.).

If the study provided medians and interquartile ranges instead of means and SDs, we imputed the means and SDs as described by Hozo et al. [20]. The combined mean and standard deviation for several subgroups in a study were computed as described by Borenstein et al. [21].

Missing or ambiguous data were solicited from authors. The corresponding author of each article received a copy of the completed validity and data-abstraction forms and was then requested to correct erroneous assessments and provide missing information when necessary.

\section{Quality assessment}

The quality of the studies included in the metaanalysis were assessed according to a modification of the Newcastle-Ottawa Quality Assessment Scale (NOS) for case-control studies as described by Wells et al. [22]. The total possible score for each article is nine points; articles with more than five points were considered of high quality, and the others were considered of low quality.

To assess the quality of the pooled evidence, the Grading of Recommendations, Assessment, Development and Evaluation (GRADE) approach was adopted [23]. We developed Summary of Findings tables with the use of the GradePro software.

\section{Statistical analysis}

Meta-analysis was performed using the Review Manager software (Vision 5.3, The Cochrane Collaboration, Oxford, United Kingdom). We used Hedge's g standardized mean differences (SMDs) as a measure of effect size because the outcomes of the studies were frequently measured by different assays and techniques. SMD becomes dimensionless and the scales become uniform across the different studies. Results were given as SMD and $95 \%$ confidence intervals $(95 \% \mathrm{CI})$.

The statistical heterogeneity was determined by the value of the $\mathrm{I}^{2}$ statistic using Hedge's test. When the statistical heterogeneity was notable $\left(\mathrm{I}^{2}>50 \%\right)$, an integrated effect was calculated with a random-effect model; otherwise, the fixed-effect model was used.

Publication bias was estimated by funnel plot asymmetry and Egger's regression test performed by Stata 14.0 software, when 10 or more studies were included in the same analysis [24]. A sensitivity analysis was also performed with Stata 14.0 software to evaluate the robustness in the conclusion of each analysis with over 10 or more studies [25]. All $P$ values were evaluated using two-tailed tests, and $p<0.05$ was set as statistically significant.

\section{RESULTS}

The flow chart of preferred reporting items for Systematic Review and Meta-Analysis was present in Figure 1. 1024 records were retrieved after the primary literature search. However, after screening the titles and abstracts, 829 studies were excluded because they were case reports, abstracts, review articles, animal studies, or irrelevant to the current analysis. The remaining 195 reports were detailed evaluated with the full text, and 130 studies were excluded according to the exclusion criteria and quality assessment. 65 articles were finally included in our analysis, which contained 33 from Asia and Oceania, 20 from Europe, 6 from Africa and 6 from North/South America. These included articles contained 11 oxidative stress markers, 2012 fertile controls and 3819 infertile patients.

The eligible studies for meta-analysis were shown in Table 1, and they were marked with NOS scores for the methodological quality assessment (Supplementary Figure 1). There were 51 studies of high quality (NOS $>5$ ), and the remaining 14 were of low quality (NOS $\leq 5$ ). 


\section{Meta-analysis of malondialdehyde concentration}

Lipids are considered to be the most susceptible macromolecules to ROS and are present in sperm plasma membrane. Oxidative damage to lipids results in lipid peroxidation, and malondialdehyde (MDA) is one of the by-products of lipid peroxidation, which has been used in various biochemical assays to monitor the degree of peroxidative damage sustained by spermatozoa [88]. There were 28 articles including 1412 infertile patients and 871 fertile controls that were used to perform the meta-analysis of seminal plasma MDA concentration [13, 26, 27, 29, 30, $33-35,39,40,43,45-47,51-58,60,62,65,66,71,72]$.

The statistical heterogeneity was notable $\left(I^{2}=95 \%\right)$, so the random-effect model was chosen to calculate the integrated effect, showing that the seminal plasma MDA concentrations in infertile patients were higher than those in control groups $(\mathrm{SMD}=1.86,95 \% \mathrm{CI}: 1.40,2.33$, $\mathrm{Z}=7.85, p<0.00001$; Figure 2). Egger's regression analysis displayed an evidence of publication bias for this marker, with no small study effect (Egger's regression intercept 6.907356, $t=2.29042,95 \% \mathrm{CI}$ 2.199367 11.61534, $P=0.006<0.05$; Figure 3). We excluded the studies of low quality $(\mathrm{NOS} \leq 5)$ [53, 57], yielding similar results and publication bias $(\mathrm{SMD}=1.96,95 \%$ CI: 1.51, $2.40, \mathrm{Z}=7.85, p<0.00001$; Egger's regression intercept 7.293577, $t=3.56,95 \% \mathrm{CI}$
3.064078 11.52308, $P=0.002<0.05$ ), so this conclusion needs to be interpreted cautiously. Meanwhile, a sensitivity analysis with a random effect model showed that the pooled estimate of the effect did not vary substantially with the exclusion of any of the studies, indicating the robustness of this result (Supplementary Figure 2).

\section{Meta-analysis of total antioxidant capacity}

The total antioxidant capacity (TAC) of seminal plasma is measured by the levels of enzymatic and nonenzymatic antioxidants. Low TAC in semen is thought to be widely involved in male infertility [89]. Seminal plasma TAC was analyzed in meta-analysis with 21 articles containing 1255 infertile patients and 553 fertile controls $[8,28,29,31,32,35,37,41-43,45,46,49,61,68,70$, $73,76-78,83]$. The random-effect model was performed to calculate the integrated effect, because of the notable statistical heterogeneity $\left(\mathrm{I}^{2}=97 \%\right)$. The TAC in seminal plasma of infertile patients was remarkably lower than that of fertile subjects (SMD $=-1.77,95 \% \mathrm{CI}:-2.49,-1.04, \mathrm{Z}$ $=4.78, p<0.00001$; Figure 4). Egger's test was performed to detect publication bias, and the results indicated no publication bias or small study effect, confirming the reliability of the conclusions (Egger's regression intercept $-6.005721, t=-1.41,95 \%$ CI $-14.89445 \sim 2.88301, P=$ $0.173>0.05$; Figure 5). A sensitivity analysis with a

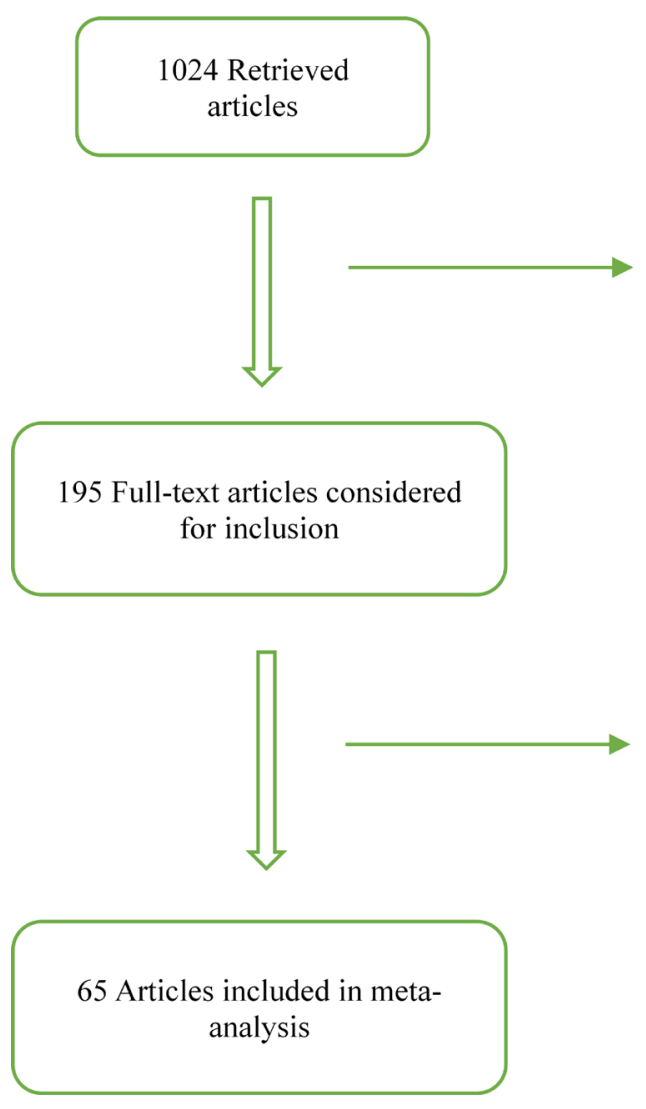

Articles excluded based on the titles or abstracts $(\mathrm{N}=829)$

$>$ Case reports; Abstracts; Review articles;

$>$ Animal studies;

$>\quad$ Irrelevant to the current analysis;

$>$ Female infertility;

Excluded articles that do not meet the inclusion criteria $(\mathrm{N}=130)$

$>\quad$ Studies of non-seminal plasma;

$>$ Studies with no control groups;

$>$ Studies of infertile patients with testicular varicocele, leukocytospermia, infection, and on antioxidant supplement;

$>\quad$ Studies with data only in graphic form;

$>$ Duplicate publications;

$>$ Outcome measure is inappropriate;

Figure 1: Flow diagram of the trial selection process. 
Table 1: Characteristics and quality assessment of the studies included in the meta-analysis

\begin{tabular}{|c|c|c|c|c|c|c|c|c|}
\hline \multirow[b]{2}{*}{ Author } & \multirow[b]{2}{*}{ Year } & \multirow[b]{2}{*}{ Country } & \multicolumn{2}{|c|}{ Simple size $(n)$} & \multicolumn{2}{|c|}{ Mean or range of age (years) } & \multirow[b]{2}{*}{ Oxidative stress biomarkers } & \multirow[b]{2}{*}{ NOS } \\
\hline & & & Fertility & Infertility & Fertility & Infertility & & \\
\hline Atig, et al. [26] & 2017 & Tunisia & 50 & 100 & $34.81 \pm 5.43$ & $39.40 \pm 5.20$ & MDA, SOD, GPX, CAT & 8 \\
\hline Fafula, et al. [27] & 2017 & Ukraine & 20 & 39 & $\mathrm{~N} / \mathrm{A}$ & $\mathrm{N} / \mathrm{A}$ & MDA, GPX, GST & 7 \\
\hline Vatannejad, et al. [28] & 2017 & Iran & 28 & 25 & $\mathrm{~N} / \mathrm{A}$ & N/A & TAC & 4 \\
\hline Fazeli, et al. [29] & 2016 & Iran & 34 & 35 & N/A & $\mathrm{N} / \mathrm{A}$ & MDA, TAC & 6 \\
\hline Micheli, et al. [30] & 2016 & Italy & 14 & 16 & $22-44$ & $22-40$ & MDA, GPX, CAT, GSH & 8 \\
\hline Riaz, et al. [31] & 2016 & Pakistan & 20 & 20 & N/A & $\mathrm{N} / \mathrm{A}$ & TAC & 5 \\
\hline Roychoudhury, et al. [32] & 2016 & USA & 46 & 279 & $37.57 \pm 11.37$ & $35.61 \pm 6.06$ & TAC & 6 \\
\hline Taken, et al. [33] & 2016 & Turkey & 22 & 30 & $30.40 \pm 4.97$ & $29.90 \pm 4.28$ & MDA, NO & 8 \\
\hline El-Taieb, et al. [34] & 2015 & Egypt & 20 & 30 & $33.5 \pm 7.69$ & $35.26 \pm 10.07$ & MDA & 8 \\
\hline Layali, et al. [35] & 2015 & Iran & 12 & 25 & $31.21 \pm 4.07$ & $29 \pm 3.37$ & MDA, TAC & 8 \\
\hline Tamilselvan, et al. [36] & 2015 & India & 10 & 10 & $30.20 \pm 2.74$ & $30.10 \pm 2.56$ & SOD, GPX & 6 \\
\hline Yousefniapasha, et al. [37] & 2015 & Iran & 33 & 30 & $24-38$ & $24-38$ & TAC, NO & 8 \\
\hline zhao, et al. [38] & 2015 & China & 40 & 40 & $24-36$ & $25-39$ & SOD & 6 \\
\hline Al-Azzawie, et al. [39] & 2014 & Iraq & 30 & 50 & N/A & $23-45$ & $\begin{array}{l}\text { MDA, SOD, GPX, CAT, GSH, } \\
\text { VC, VE }\end{array}$ & 7 \\
\hline Collodel, et al. [40] & 2014 & Italy & 14 & 20 & $24-45$ & $24-40$ & MDA & 8 \\
\hline Eroglu, et al. [41] & 2014 & Turkey & 15 & 44 & $32.5 \pm 5.3$ & $31.2 \pm 4.9$ & TAC & 8 \\
\hline Mostafa, et al. [13] & 2014 & Egypt & 20 & 40 & $30.15 \pm 6.8$ & $30.9 \pm 5.1$ & MDA, GPX & 8 \\
\hline Türk, et al. [42] & 2014 & Estonia & 27 & 32 & $31.0 \pm 2.0$ & $31.0 \pm 1.5$ & TAC, GPX & 8 \\
\hline Jiao, et al. [43] & 2013 & China & 21 & 72 & $25-30$ & $20-35$ & MDA, TAC & 7 \\
\hline Kullisaar, et al. [44] & 2013 & Estonia & 27 & 32 & $30.0 \pm 5.2$ & $32.2 \pm 6.6$ & NO & 8 \\
\hline Mehrotra, et al. [45] & 2013 & India & 15 & 40 & $30.79 \pm 1.83$ & $36.53 \pm 3.39$ & TAC, MDA & 8 \\
\hline Benedetti, et al. [46] & 2012 & Italy & 12 & 31 & $40 \pm 5$ & $41 \pm 6$ & TAC, MDA, VE & 8 \\
\hline Gao, et al. [47] & 2012 & China & 100 & 120 & $29 \pm 3.1$ & $30 \pm 3.3$ & MDA, SOD & 7 \\
\hline Khalil, et al. [48] & 2012 & Egypt & 40 & 80 & $20-35$ & $20-35$ & SOD, GPX, GST & 7 \\
\hline Shamsi, et al. [49] & 2012 & India & 76 & 93 & $29.14 \pm 1.78$ & $31.75 \pm 4.82$ & TAC & 8 \\
\hline Shete, et al. [50] & 2012 & India & 30 & 50 & $21-58$ & $21-58$ & GSH & 7 \\
\hline You, et al. [51] & 2012 & China & 50 & 30 & $27.5 \pm 4.7$ & $27 \pm 4.5$ & MDA & 6 \\
\hline Badade, et al. [52] & 2011 & India & 30 & 30 & $21-45$ & $21-45$ & MDA, SOD & 8 \\
\hline $\mathrm{Li}$, et al. [53] & 2011 & China & 30 & 30 & $24-36$ & $24-38$ & MDA, SOD & 5 \\
\hline Tang, et al. [54] & 2011 & China & 30 & 65 & $29.2 \pm 8.7$ & $26.5 \pm 5.6$ & MDA, NO & 8 \\
\hline Abdul-rasbeed, et al. [55] & 2010 & Iraq & 39 & 60 & $31.87 \pm 3.76$ & $31.94 \pm 4.21$ & MDA & 7 \\
\hline Ahmad, et al. [56] & 2010 & India & 75 & 75 & $25-40$ & $25-40$ & $\begin{array}{l}\text { MDA, SOD, GPX, CP, GSH, } \\
\text { VC, VE }\end{array}$ & 8 \\
\hline Abdallah, et al. [57] & 2009 & Tunisia & 9 & 93 & $\mathrm{~N} / \mathrm{A}$ & $\mathrm{N} / \mathrm{A}$ & MDA, SOD, CAT & 5 \\
\hline Elshal, et al. [58] & 2009 & Egypt & 16 & 70 & $<45$ & $<45$ & MDA, SOD, CAT, GSH & 7 \\
\hline El-Taieb, et al. [59] & 2009 & Austria & 10 & 20 & $35.6 \pm 5.72$ & $38.85 \pm 10.52$ & $\mathrm{CP}$ & 6 \\
\hline Kumar, et al. [60] & 2009 & India & 30 & 33 & 31 & 30.5 & MDA, SOD, GPX, CAT & 8 \\
\hline Mahfouz, et al. [61] & 2009 & USA & 55 & 42 & $\mathrm{~N} / \mathrm{A}$ & $\mathrm{N} / \mathrm{A}$ & TAC & 5 \\
\hline Nouri, et al. [62] & 2008 & Iran & 40 & 60 & $37.1 \pm 4$ & $34.2 \pm 3.4$ & MDA, VC, VE & 7 \\
\hline Tavilani, et al. [63] & 2008 & Iran & 15 & 30 & $20-40$ & $20-40$ & SOD, CAT, GPX & 8 \\
\hline Amiri, et al. [64] & 2007 & Iran & 70 & 45 & $31.40 \pm 4.60$ & $33.20 \pm 5.50$ & NO & 6 \\
\hline Aydemir, et al. [65] & 2007 & Turkey & 60 & 52 & $40.00 \pm 7.00$ & $39.12 \pm 5.94$ & MDA, GSH, CP & 8 \\
\hline Khosrowbeygi, et al. [8] & 2007 & Iran & 16 & 46 & $32.06 \pm 3.91$ & $33.81 \pm 5.84$ & TAC, SOD, CAT & 8 \\
\hline Kiziler, et al. [66] & 2007 & Turkey & 45 & 50 & $40.22 \pm 9.0$ & $39.54 \pm 6.5$ & MDA, CP, GSH & 8 \\
\hline Murawski, et al. [67] & 2007 & Poland & 5 & 10 & $\mathrm{~N} / \mathrm{A}$ & N/A & SOD & 4 \\
\hline Verit, et al. [68] & 2006 & Turkey & 20 & 30 & $31.60 \pm 5.43$ & $31.66 \pm 5.06$ & TAC & 5 \\
\hline Mehraban, et al. [69] & 2005 & Iran & 40 & 40 & $27.9 \pm 4.44$ & $30.4 \pm 5.17$ & NO & 8 \\
\hline Shi, et al. $[70]$ & 2005 & China & 28 & 113 & 26-38 & $25-40$ & TAC & 5 \\
\hline
\end{tabular}




\begin{tabular}{|c|c|c|c|c|c|c|c|c|}
\hline Tavilani, et al. [71] & 2005 & Iran & 15 & 35 & N/A & N/A & MDA & 6 \\
\hline $\mathrm{Li}$, et al. [72] & 2004 & China & 18 & 81 & $29.4 \pm 3.7$ & $30.4 \pm 3.1$ & MDA & 7 \\
\hline Koca, et al. [73] & 2003 & Turkey & 20 & 30 & N/A & N/A & TAC & 7 \\
\hline Raijmakers, et al. [74] & 2003 & Netherlands & 25 & 25 & $34.25 \pm 3.75$ & $33.50 \pm 3.50$ & GSH & 7 \\
\hline Giannattasio, et al. [75] & 2002 & Italy & 14 & 20 & $25-37$ & $28-37$ & GPX & 7 \\
\hline Siciliano, et al. [76] & 2001 & Italy & 25 & 90 & $20-40$ & $20-40$ & TAC, SOD, CAT & 6 \\
\hline Pasqualotto, et al. [77] & 2000 & USA & 19 & 36 & N/A & N/A & TAC & 6 \\
\hline zini, et al. [6] & 2000 & Canada & 12 & 105 & $43 \pm 2$ & $36 \pm 1$ & SOD, CAT & 8 \\
\hline Sharma, et al. [78] & 1999 & USA & 24 & 28 & N/A & $\mathrm{N} / \mathrm{A}$ & TAC & 7 \\
\hline Zhang, et al. [79] & 1999 & China & 108 & 350 & $27.56 \pm 2.19$ & $28.15 \pm 3.08$ & SOD & 5 \\
\hline Alkan, et al. [80] & 1997 & Turkey & 10 & 18 & $28.4 \pm 0.7$ & $32.6 \pm 1.5$ & SOD, CAT, GPX & 8 \\
\hline Lewis, et al. [81] & 1997 & UK & 18 & 41 & N/A & N/A & $\mathrm{VC}, \mathrm{VE}$ & 5 \\
\hline Kurpisz, et al. [82] & 1996 & Poland & 10 & 63 & N/A & N/A & SOD & 6 \\
\hline Smith, et al. [83] & 1996 & Chile & 15 & 101 & N/A & $25-45$ & TAC & 4 \\
\hline Fan, et al. [84] & 1995 & China & 15 & 55 & $24-34$ & $26-35$ & SOD & 5 \\
\hline Chen, et al. [85] & 1994 & China & 137 & 245 & 29.8 & 32.3 & SOD & 4 \\
\hline Jeulin, et al. [86] & 1989 & France & 11 & 14 & N/A & N/A & CAT & 5 \\
\hline Li, et al. [87] & 1989 & China & 27 & 75 & $26-40$ & $22-40$ & SOD & 5 \\
\hline
\end{tabular}

NOS: Newcastle-Ottawa Quality Assessment Scale; MDA: malondialdehyde; TAC: total antioxidant capacity; SOD: superoxide dismutase; CAT: catalase; GPX: glutathione peroxidase; GST: glutathione S-transferase; GSH: glutathione; NO: nitric oxide; CP: carbonyl protein; VC: vitamin C; VE: vitamin E; N/A: not available.

\begin{tabular}{|c|c|c|c|c|c|c|c|c|c|c|c|}
\hline \multirow[b]{2}{*}{ Study or Subgroup } & \multicolumn{3}{|c|}{ Ifertile patients } & \multicolumn{3}{|c|}{ Fertile controls } & \multirow{2}{*}{\multicolumn{2}{|c|}{$\begin{array}{c}\text { Std. Mean Difference } \\
\text { Weight IV, Random, } 95 \% \mathrm{Cl}\end{array}$}} & \multirow{2}{*}{\multicolumn{2}{|c|}{$\begin{array}{l}\text { Std. Mean Difference } \\
\text { IV. Random, } 95 \% \mathrm{Cl}\end{array}$}} & \\
\hline & Mean & SD & Total & Mean & SD & Total & & & & & \\
\hline Li, et al. 2011 & 7.62 & 1.52 & 30 & 10.5 & 2.33 & 30 & $3.7 \%$ & $-1.45[-2.02,-0.87]$ & $\pi$ & & \\
\hline Collodel, et al. 2014 & 0.62 & 1.58 & 20 & 0.46 & 0.04 & 14 & $3.6 \%$ & $0.13[-0.56,0.81]$ & & + & \\
\hline Tavilani, et al. 2005 & 1.35 & 0.42 & 35 & 1.2 & 0.3 & 15 & $3.6 \%$ & $0.38[-0.23,0.99]$ & & $F$ & \\
\hline Fazeli, et al. 2016 & 3.4 & 1.5 & 35 & 2.6 & 1 & 34 & $3.7 \%$ & $0.62[0.13,1.10]$ & & + & \\
\hline Tang, et al. 2011 & 24.35 & 10.25 & 65 & 18.15 & 7.39 & 30 & $3.7 \%$ & $0.65[0.21,1.09]$ & & $r$ & \\
\hline Mehrotra, et al. 2013 & 3.28 & 1.22 & 40 & 2.48 & 0.74 & 15 & $3.6 \%$ & $0.71[0.10,1.32]$ & & - & \\
\hline Micheli, et al. 2016 & 0.59 & 0.09 & 16 & 0.53 & 0.05 & 14 & $3.5 \%$ & $0.79[0.04,1.54]$ & & - & \\
\hline Benedetti, et al. 2012 & 1.2 & 0.28 & 31 & 0.98 & 0.16 & 12 & $3.6 \%$ & $0.85[0.16,1.54]$ & & - & \\
\hline Atig, et al. 2017 & 2.536 & 1.298 & 100 & 1.54 & 0.68 & 50 & $3.8 \%$ & $0.88[0.52,1.23]$ & & $=$ & \\
\hline Gao, et al. 2012 & 160 & 71 & 120 & 110 & 12 & 100 & $3.8 \%$ & $0.94[0.66,1.22]$ & & $\pi$ & \\
\hline Taken, et al. 2016 & 9.68 & 2.87 & 30 & 6.63 & 2.99 & 22 & $3.6 \%$ & $1.03[0.44,1.62]$ & & $r$ & \\
\hline Jiao, et al. 2013 & 2.32 & 1.46 & 72 & 0.78 & 0.31 & 21 & $3.7 \%$ & $1.18[0.66,1.69]$ & & $r$ & \\
\hline Layali, et al. 2015 & 0.94 & 0.28 & 25 & 0.62 & 0.18 & 12 & $3.5 \%$ & $1.24[0.49,1.99]$ & & - & \\
\hline Mostafa, et al. 2014 & 2.71 & 0.9 & 40 & 1.57 & 0.7 & 20 & $3.6 \%$ & $1.34[0.75,1.93]$ & & $r$ & \\
\hline El-Taieb, et al. 2015 & 2.69 & 0.87 & 30 & 1.68 & 0.4 & 20 & $3.6 \%$ & $1.38[0.75,2.01]$ & & $r$ & \\
\hline Kiziler, et al. 2007 & 0.62 & 0.18 & 50 & 0.39 & 0.08 & 45 & $3.7 \%$ & $1.61[1.14,2.07]$ & & 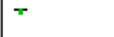 & \\
\hline Nouri, et al. 2008 & 1.9 & 0.35 & 60 & 1.4 & 0.2 & 40 & $3.7 \%$ & $1.66[1.19,2.12]$ & & $r$ & \\
\hline Elshal, et al. 2009 & 6.96 & 3.22 & 70 & 1.96 & 0.78 & 16 & $3.6 \%$ & $1.69[1.09,2.29]$ & & $T$ & \\
\hline Aydemir, et al. 2007 & 0.62 & 0.16 & 52 & 0.4 & 0.06 & 60 & $3.7 \%$ & $1.86[1.41,2.31]$ & & 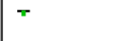 & \\
\hline Abdul-rasbeed, et al. 2010 & 12.105 & 2.126 & 60 & 8.517 & 0.062 & 39 & $3.7 \%$ & $2.15[1.64,2.65]$ & & 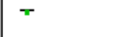 & \\
\hline Abdallah, et al. 2009 & 2.73 & 0.7 & 93 & 1.22 & 0.06 & 9 & $3.5 \%$ & $2.23[1.48,2.98]$ & & $T$ & \\
\hline Li, et al. 2004 & 1.3 & 0.27 & 81 & 0.64 & 0.11 & 18 & $3.6 \%$ & $2.62[1.99,3.26]$ & & 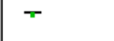 & \\
\hline Al-Azzawie, et al. 2014 & 5.64 & 1.97 & 50 & 0.82 & 0.22 & 30 & $3.6 \%$ & $3.05[2.38,3.71]$ & & $r$ & \\
\hline Ahmad, et al. 2010 & 3.06 & 0.54 & 75 & 1.74 & 0.19 & 75 & $3.7 \%$ & $3.24[2.75,3.74]$ & & 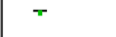 & \\
\hline Fafula, et al. 2017 & 300.57 & 40.21 & 39 & 162.2 & 15.6 & 20 & $3.4 \%$ & $4.01[3.09,4.93]$ & & - & \\
\hline Badade, et al. 2011 & 5.34 & 0.95 & 30 & 1.67 & 0.56 & 30 & $3.3 \%$ & $4.65[3.65,5.64]$ & & $T$ & \\
\hline Kumar, et al. 2009 & 0.273 & 0.03 & 33 & 0.126 & 0.02 & 30 & $3.2 \%$ & $5.64[4.51,6.77]$ & & $\rightarrow$ & \\
\hline You, et al. 2012 & 22.15 & 1.94 & 30 & 5.4 & 1.12 & 50 & $2.4 \%$ & $11.22[9.38,13.06]$ & & & \\
\hline Total $(95 \% \mathrm{Cl})$ & & & 1412 & & & 871 & $100.0 \%$ & $1.86[1.40,2.33]$ & & 1 & \\
\hline $\begin{array}{l}\text { Heterogeneity: } \text { Tau }^{2}=1.45 \text {; } \\
\text { Test for overall effect: } Z=7 \text {. }\end{array}$ & $\begin{array}{l}C h i^{2}=518 \\
85(P<0 .\end{array}$ & $\begin{array}{l}8.37, \mathrm{df}= \\
.00001)\end{array}$ & $=27(P$ & $0<0.00$ & 001); $\left.\right|^{2}=$ & $=95 \%$ & & & $\begin{array}{ccc}-10 & -5 & 0 \\
\text { Favours [Fertility] }\end{array}$ & Favours [Inf & 10 \\
\hline
\end{tabular}

Figure 2: Meta-analysis of studies addressing MDA levels in seminal plasma of infertile patients and control subjects. Results are shown as standardized mean differences (SMDs). 
random effect model was performed to calculate the pooled estimate of the effect after exclusion of each of the studies, which showed no vary substantially results, indicating the robustness of this result (Supplementary Figure 3).

\section{Meta-analysis of superoxide dismutase activity}

Superoxide dismutase (SOD) scavenges both intracellular and extracellular superoxide radicals and prevents the lipid peroxidation of plasma membrane [90]. Tween-one reports were included in the meta-analysis of SOD activity in seminal plasma with 1808 infertile patients and 760 fertile controls $[6,8,26,38,39,47,48$, $52,53,56-58,60,63,67,76,79,80,82,84,85,87]$. There exhibited a notable statistical heterogeneity $\left(\mathrm{I}^{2}=97 \%\right)$, and thus a random-effect model was performed to calculate the integrated effect. The results indicated no statistically significant difference of the superoxide dismutase (SOD) activity in infertile patients and fertile subjects (SMD = $-0.51,95 \% \mathrm{CI}:-1.08,0.05, \mathrm{Z}=1.78, P=0.17>0.05$; Figure 6). Meanwhile, the publication bias was evaluated through the Egger's test, showing no statistically significant evidence of publication bias or small study effect among these studies (Egger's regression intercept 0.8459985, $t$ $=0.32,95 \% \mathrm{CI}-4.621949 \sim 6.313946, P=0.750>0.05$; Figure 7). The pooled estimate of the effect did not vary substantially displayed by a sensitivity analysis with a random effect model with the exclusion of each one of the studies, indicating the robustness of this result (Supplementary Figure 4).

\section{Meta-analysis of catalase activity}

Catalase detoxifies both intracellular and extracellular $\mathrm{H}_{2} \mathrm{O}_{2}$ to water and oxygen [91]. In addition, catalase activates NO-induced sperm capacitation, which is a

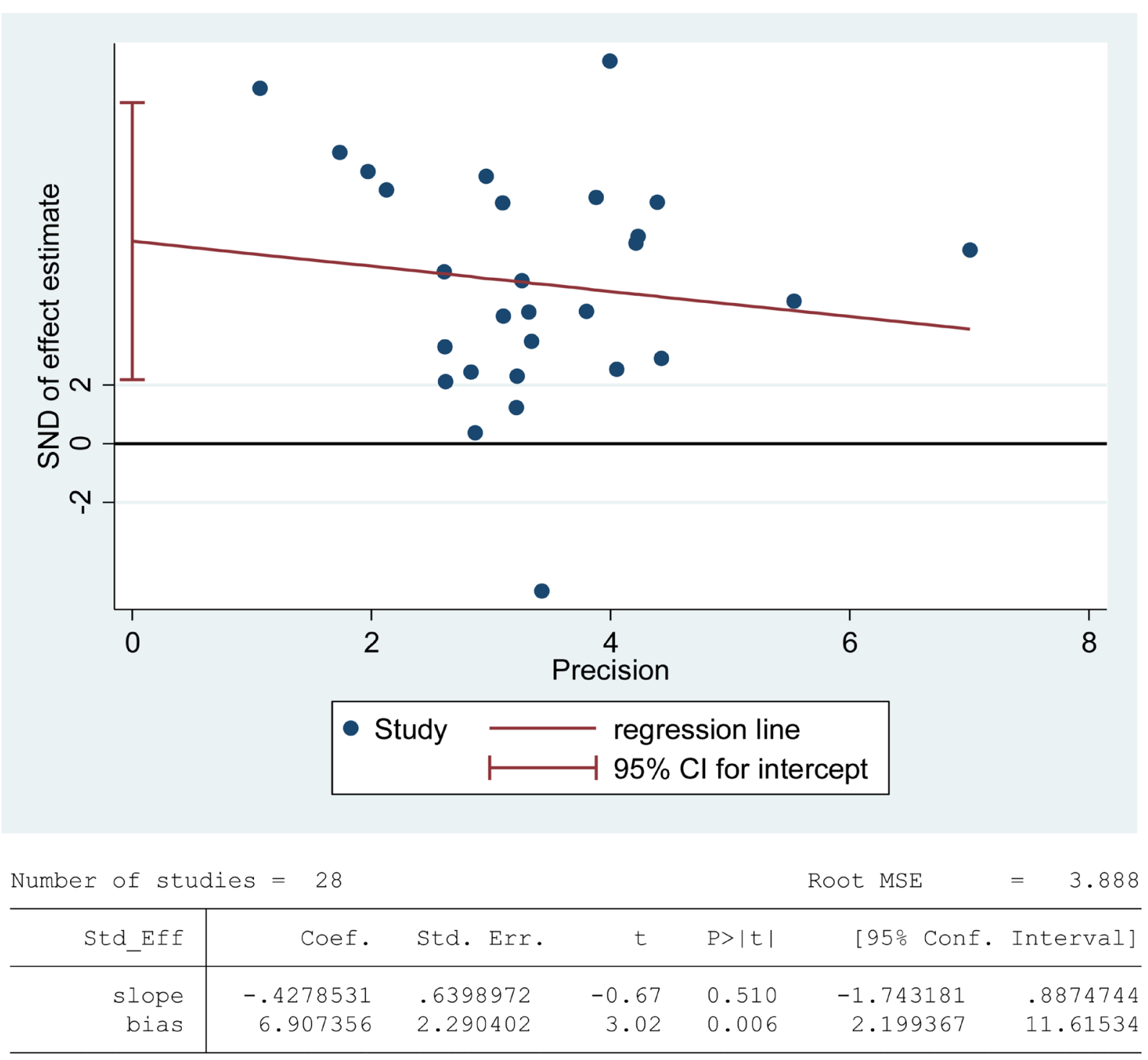

Figure 3: Evidence of publication bias in MDA concentration was assessed using funnel plot asymmetry and Egger's regression. 
complex mechanism involving $\mathrm{H}_{2} \mathrm{O}_{2}$ [92]. Thirteen studies were included in the meta-analysis with 740 infertile patients and 263 fertile controls to analyze the catalase activity in seminal plasma $[6,8,26,30,39$, 56-58, 60, 63, 76, 80, 86]. The statistical heterogeneity was notable $\left(\mathrm{I}^{2}=96 \%\right)$, and the integrated effect was calculated from a random-effect model hereby. Statistically lower catalase activity was present in infertile subjects than that in the control ones (SMD $=-1.91$, 95\% CI: $-2.79,-1.04, \mathrm{Z}=4.28, p<0.0001$; Figure 8). Egger's test was also performed to evaluate the publication bias, displaying no statistically significant evidence of publication bias and small study effect among these studies (Egger's regression intercept $-6.19329, t=-2.11,95 \% \mathrm{CI}$ $-12.66441 \sim 0.2778316, P=0.059>0.05$; Figure 9). A sensitivity analysis with a random effect model was performed to calculate the pooled estimate of the effect after exclusion of each of the studies, which showed no vary substantially results, indicating the robustness of this result (Supplementary Figure 5).

\section{Meta-analysis of glutathione peroxidase activity}

Glutathione peroxidase (GPX) reduces lipid hydroperoxides to their corresponding alcohols and free hydrogen peroxide to water [93]. 468 infertile patients and 290 fertile subjects from 12 studies were included in the meta-analysis to evaluate the GPX activity in seminal plasma $[13,26,27,30,36,39,42,48,60,63,75,80]$. Notable statistical heterogeneity was present $\left(\mathrm{I}^{2}=97 \%\right)$, so the integrated effect was calculated from a randomeffect model. The GPX activity was significantly lower in infertile subjects when compared to fertile controls (SMD $=-1.96,95 \% \mathrm{CI}:-3.00,-0.92, \mathrm{Z}=3.68, P=0.0002<$ 0.05 ; Figure 10). The publication bias was of significant existence according to an Egger's test (Egger's regression intercept $-8.752643, t=-2.52$, 95\% CI -16.50495 $1.000335, P=0.031<0.05$; Figure 11 ), so this conclusion need to be interpreted cautiously. Meanwhile, the pooled estimate of the effect did not vary substantially displayed by a sensitivity analysis with a random effect model with the exclusion of each one of the studies, indicating the robustness of this result (Supplementary Figure 6).

\section{Meta-analysis of reduced glutathione concentration}

Reduced glutathione (GSH) is able to react directly with cytotoxic aldehydes produced during lipid peroxidation, and thus protects the free sulphydryl groups on the sperm plasma membrane. Moreover, GSH acts to preserve $\mathrm{SH}$ groups of protein in the reduced state by means of disulfide interchange [94]. Eight studies were included in the meta-analysis to evaluate the reduced GSH concentration in seminal plasma, containing 388 infertile patients and 245 fertile controls [30, 39, 50, 56, 58, 65, 66, 74]. Remarkably evidence of heterogeneity was observed $\left(\mathrm{I}^{2}=93 \%\right)$, so the integrated effect was calculated from a random-effect model. The GSH concentration in infertile

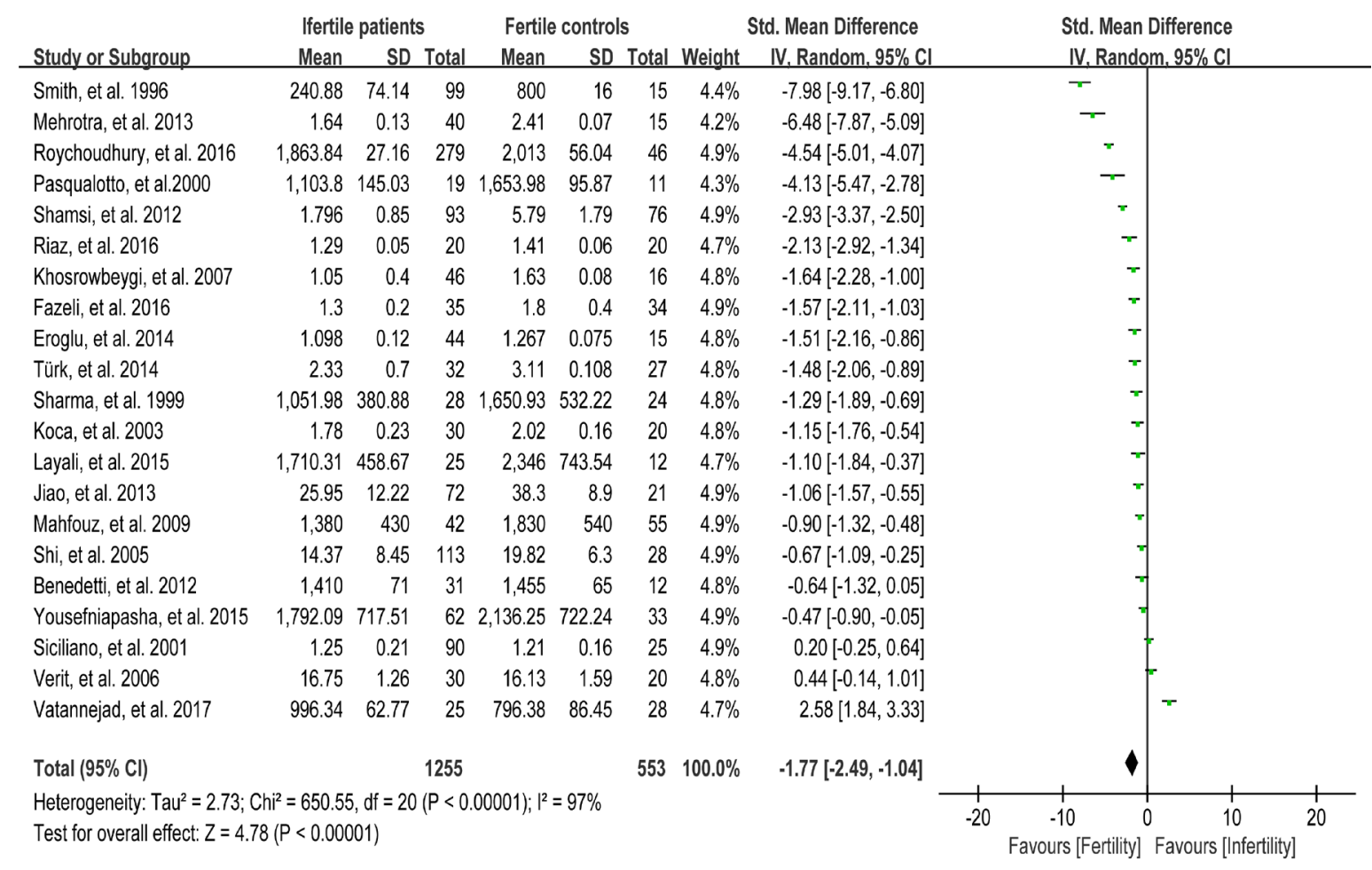

Figure 4: Meta-analysis of studies addressing TAC in seminal plasma of infertile patients and control subjects. Results are shown as standardized mean differences (SMDs). 
patients was lower than that in fertile controls (SMD $=-1.68,95 \% \mathrm{CI}:-2.40,-0.97, \mathrm{Z}=4.63, p<0.00001$; Figure 12).

\section{Meta-analysis of nitric oxide concentration}

Nitric oxide (NO) is one of the reactive oxygen species that have been implicated in variety of physiologic cell signaling mechanisms in many tissues. Excessive NO could cause sperm hypomotility and reduce fertility in humans [95]. Six studies were included in the metaanalysis to evaluate the NO concentration in seminal plasma, containing 326 infertile patients and 222 fertile controls $[33,37,44,54,64,69]$. The heterogeneity was notable $\left(\mathrm{I}^{2}=87 \%\right)$, so the integrated effect was calculated from a random-effect model. The NO concentration was found to be much higher in infertile patients when compared with fertile controls $(\mathrm{SMD}=0.89,95 \% \mathrm{CI}$ : $0.35,1.43, Z=3.24, P=0.001<0.05$; Figure 13$)$. The controls from the two studies were of unproven fertility $[54,64]$, and exclusion of these studies yielded the similar results but with much less heterogeneity (NO concentration decreased in infertile patients; $\mathrm{SMD}=0.55$, 95\% CI: $0.31,0.79, \mathrm{Z}=4.52, p<0.00001 ; I^{2}=40 \%$; fixed-effect model), indicating that the fertility of controls may be the source of heterogeneity.

\section{Meta-analysis of vitamin $\mathbf{E}$ concentration}

Vitamin E (VE) is a chain-breaking antioxidant in the sperm membranes and appears to scavenge superoxide, $\mathrm{H}_{2} \mathrm{O}_{2}$, and hydroxyl radicals [96]. Five studies were included in the meta-analysis to evaluate the VE concentration in seminal plasma, containing 257 infertile patients and 175 fertile controls $[39,46,56,62,81]$. The heterogeneity was notable $\left(\mathrm{I}^{2}=94 \%\right)$, so a random-effect model was performed to calculate the integrated effect, showing that the VE concentration was statistically lower in infertile patients than that in fertile controls (SMD $=-1.48,95 \% \mathrm{CI}:-2.45,-0.51$, $\mathrm{Z}=2.98, P=0.003<0.05$; Figure 14 ).

\section{Meta-analysis of vitamin $\mathbf{C}$ concentration}

Vitamin C (VC) is also an important chain-breaking antioxidant that can neutralize hydroxyl, superoxide, and hydrogen peroxide radicals, and prevent sperm agglutination [96]. Four studies were included in the meta-analysis to evaluate the VC concentration in seminal plasma, containing 226 infertile patients and 163 fertile controls [39, 56, 62, 81]. A fixed-effect model was performed as there was no evidence of heterogeneity among these studies $\left(I^{2}=32 \%\right)$, showing that the VC concentration was statistically lower in infertile patients

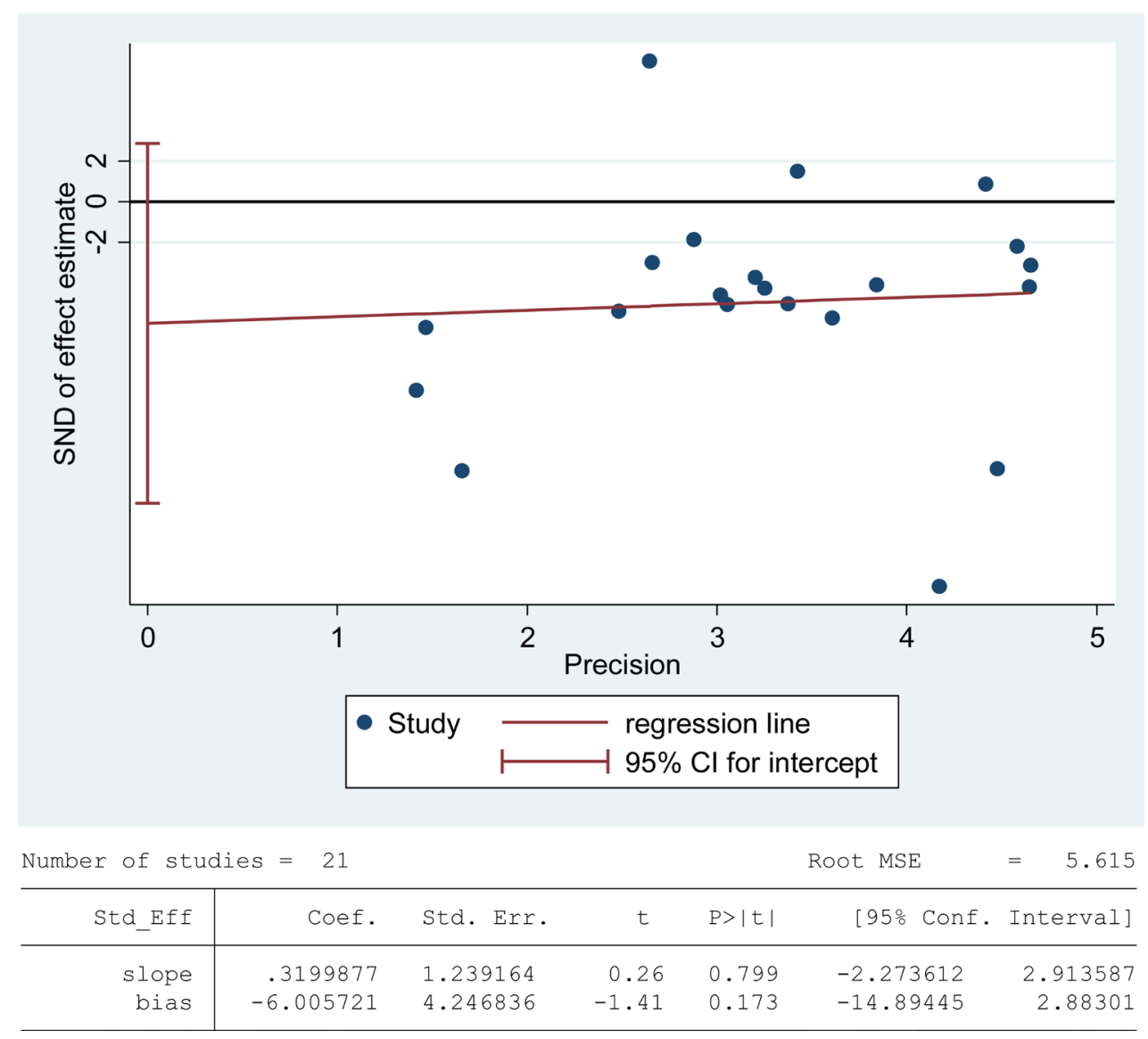

Figure 5: Evidence of publication bias in TAC was assessed using funnel plot asymmetry and Egger's regression. 
than that in fertile controls (SMD $=-1.12,95 \% \mathrm{CI}:-1.34$, $-0.90, Z=10.03, p<0.00001$; Figure 15).

\section{Meta-analysis of carbonyl protein concentration}

Protein carbonyl content is actually the most universal indicator and by far the most commonly used marker of protein oxidation [97]. Accumulation of protein carbonyls has been observed in many human diseases including Alzheimer's disease (AD), diabetes, and male infertility [98]. Four studies were included in the meta-analysis to evaluate the carbonyl protein (CP) concentration in seminal plasma, containing 197 infertile patients and 190 fertile controls $[56,59,65,66]$. A fixedeffect model was performed as there was no evidence of heterogeneity among these studies $\left(\mathrm{I}^{2}=13 \%\right)$. And, significantly higher CP concentration was observed in the infertile patients than that in controls $(\mathrm{SMD}=2.09,95 \%$ CI: 1.84, 2.34, $\mathrm{Z}=16.31, p<0.00001$; Figure 16).

\section{Meta-analysis of glutathione S-transferase activity}

Glutathione S-transferase (GST) functions to detoxify xenobiotics by catalyzing the nucleophilic which is attacked by GSH on electrophilic carbon, sulfur, or nitrogen atoms of said nonpolar xenobiotic substrates, thereby preventing their interaction with crucial cellular proteins or nucleic acids [99]. Reduced activity of GST may lead to sperm membrane damage, resulting in male infertility [66]. Seminal plasma GST activity was analyzed in meta-analysis with 4 articles containing 221 infertile patients and 145 fertile controls $[27,48,65,66]$. The heterogeneity was observed $\left(I^{2}=95 \%\right)$, so the integrated effect was calculated by a random-effect model. The results indicated that the GST activity was lower in infertile patients than that in fertile controls (SMD $=-1.62,95 \% \mathrm{CI}:-2.83,-0.41, \mathrm{Z}=2.63$, $P=0.009<0.05 ;$ Figure 17)

\section{DISCUSSION}

High ROS levels and oxidative stress have been implicated in the pathophysiology of male infertility and correlated with sperm DNA damage, impaired fertilization and embryo development, low rates of implantation and occurrence of miscarriage [100, 101]. In spite of abundant studies related, it is not well defined how changes in different antioxidants in seminal plasma are correlated with male infertility, and contradictory conclusions could always be found. This may due to the low number of patients and different types of infertility included in these published studies. However, a large-scale systematic

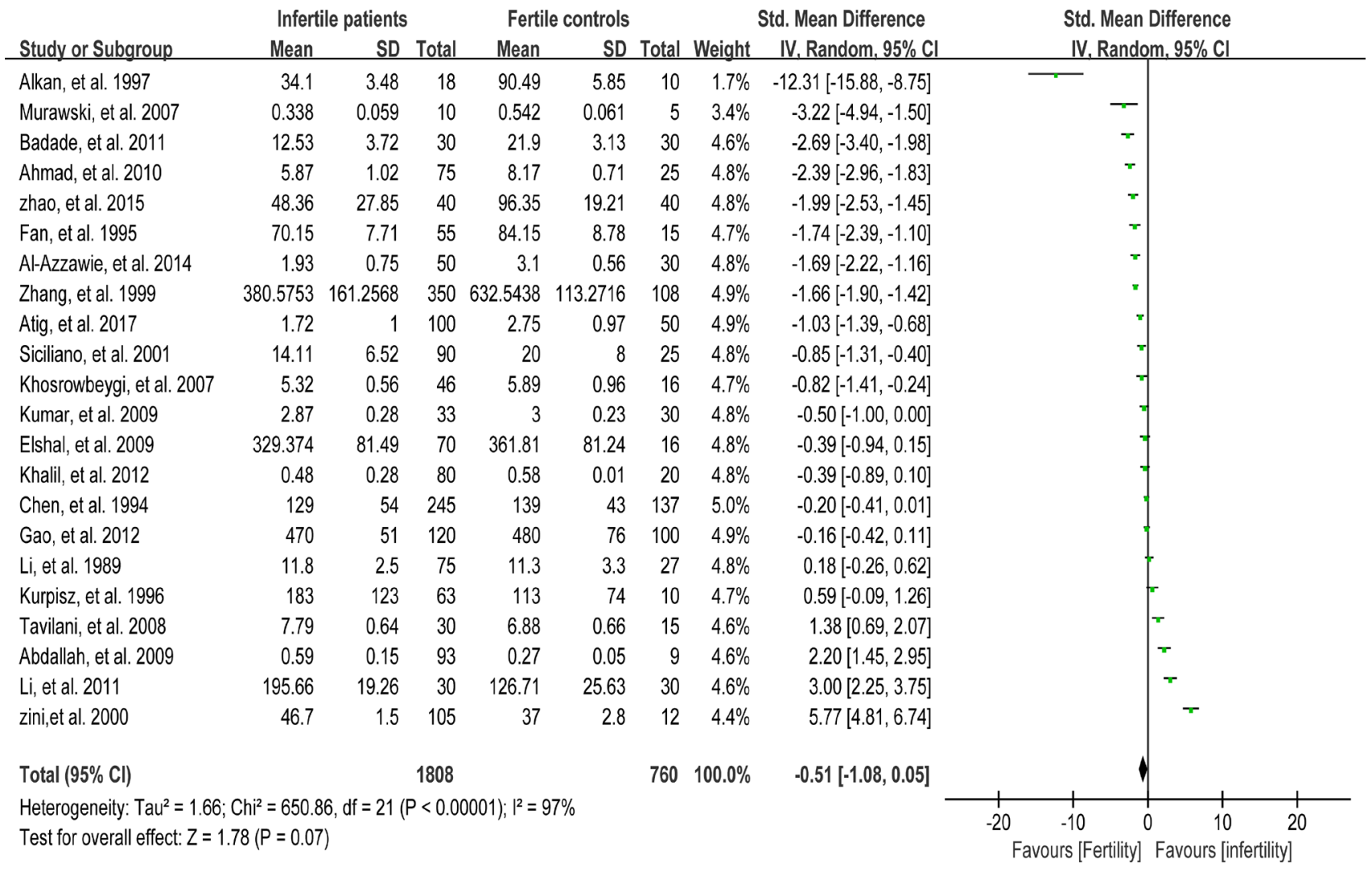

Figure 6: Meta-analysis of studies addressing SOD activity in seminal plasma of infertile patients and control subjects. Results are shown as standardized mean differences (SMDs). 
study that could address this query is not available, so we reviewed existing literatures and performed a metaanalysis on research studies that reported male infertility associated oxidative stress markers in seminal plasma. With 11 oxidative stress markers obtained from 52 individual studies that included a total of 1428 fertile controls and 2563 infertile patients, our meta-analysis may shed some light into this important issue.

ROS/RNS, as major causes of oxidative stress, plays an important role in many physiological cell processes under a certain concentration, and produce adverse modifications to cell components, such as lipids, proteins, and DNAs. Meta-analysis of these studies has shown that the concentration of seminal NO was significantly increased in infertility patient when compared with fertility controls. Few reports addressed the ROS concentration in seminal plasma, but many studies that had detected the ROS levels in spermatozoa indicated its higher concentration in infertility patients when compared with control ones [10, 49, 102-105]. Accordingly, we could speculate that the ROS concentration is also higher in the seminal plasma of infertility patients, as ROS could easily diffuses across the sperm plasma membrane [106]. Oxidative damages were evaluated in our meta-analysis, which showed that the by-products of lipid and protein peroxidation, MDA and protein carbonyls, were highly accumulated in seminal plasma of infertility patients. On the other hand, $8-\mathrm{OHdG}$, a major NDA oxidation product, was rarely reported in seminal plasma. Vatannejad, et $a l$. has noticed an increased level of $8-\mathrm{OHdG}$ in seminal plasma of infertility patients [107], but more studies are required. Similarly, the level of 8-isoprostane, a stable end product of oxidized lipids derived from arachidonic acid, in seminal plasma was reported to increase by Khosrowbeygi et al. [108]. All these findings demonstrate the evidences of oxidative stress be present in seminal plasma of infertility patients.

To counteract the harmful effects of oxidative stress, some strategies like prevention of damage, repair mechanism to alleviate the oxidative damages, physical protection mechanism against damage, and most importantly, the antioxidant defense mechanisms, are

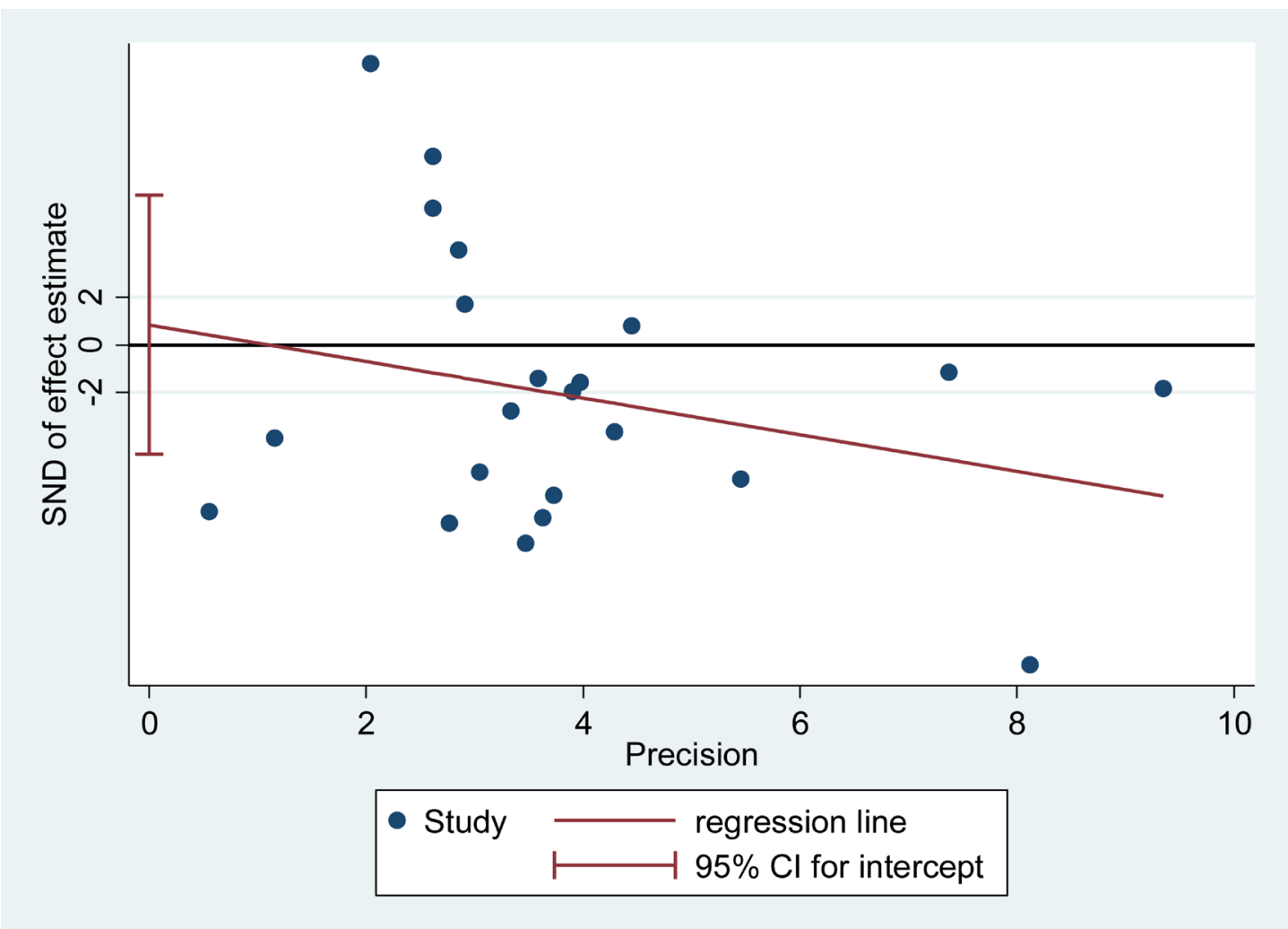

\begin{tabular}{r|rrrrrr} 
Number of studies $=$ & \multicolumn{1}{c}{ R2 } & & Root MSE & $=$ & 5.759 \\
\hline Std_Eff & Coef. & Std. Err. & $t$ & P $>|t|$ & [95\% Conf. Interval] \\
\hline slope & -.7748235 & .5979344 & -1.30 & 0.210 & -2.022093 & .4724457 \\
bias & .8459985 & 2.621306 & 0.32 & 0.750 & -4.621949 & 6.313946 \\
\hline
\end{tabular}

Figure 7: Evidence of publication bias in SOD activity was assessed using funnel plot asymmetry and Egger's regression. 


\begin{tabular}{|c|c|c|c|c|c|c|c|c|c|c|}
\hline \multirow[b]{2}{*}{ Study or Subgroup } & \multicolumn{3}{|c|}{ Infertile patients } & \multicolumn{3}{|c|}{ Fertile controls } & \multicolumn{2}{|c|}{ Std. Mean Difference } & \multirow{2}{*}{\multicolumn{2}{|c|}{$\begin{array}{r}\text { Std. Mean Difference } \\
\text { IV. Random, } 95 \% \mathrm{Cl}\end{array}$}} \\
\hline & Mean & SD & Total & Mean & SD & Total & Weight & IV. Random, $95 \% \mathrm{Cl}$ & & \\
\hline Alkan, et al. 1997 & 32.23 & 3.07 & 18 & 65.53 & 5.49 & 10 & $5.2 \%$ & $-7.94[-10.31,-5.56]$ & & \\
\hline Khosrowbeygi, et al. 2007 & 14.4 & 0.93 & 46 & 22.58 & 2.2 & 16 & $7.2 \%$ & $-5.92[-7.14,-4.71]$ & $\rightarrow$ & \\
\hline Kumar, et al. 2009 & 239 & 11.96 & 33 & 307.5 & 15.29 & 30 & $7.6 \%$ & $-4.96[-5.98,-3.94]$ & - & \\
\hline Elshal, et al. 2009 & 80.52 & 13.4 & 70 & 126.27 & 13.56 & 16 & $7.9 \%$ & $-3.38[-4.13,-2.63]$ & $T$ & \\
\hline zini,et al. 2000 & 326 & 17 & 105 & 369 & 49 & 12 & $8.1 \%$ & $-1.93[-2.58,-1.28]$ & $\pi$ & \\
\hline Tavilani, et al. 2008 & 0.18 & 0.04 & 30 & 0.3 & 0.1 & 15 & $8.0 \%$ & $-1.79[-2.52,-1.06]$ & $\pi$ & \\
\hline Jeulin, et al. 1989 & 62 & 36 & 14 & 129 & 59 & 11 & $7.8 \%$ & $-1.37[-2.26,-0.48]$ & $r$ & \\
\hline Ahmad, et al. 2010 & 7.7 & 1.36 & 75 & 9.18 & 0.93 & 25 & $8.2 \%$ & $-1.16[-1.64,-0.68]$ & $T$ & \\
\hline Al-Azzawie, et al. 2014 & 0.198 & 0.107 & 50 & 0.34 & 0.16 & 30 & $8.2 \%$ & $-1.09[-1.57,-0.60]$ & $T$ & \\
\hline Abdallah, et al. 2009 & 1.17 & 0.24 & 93 & 1.3 & 0.22 & 9 & $8.0 \%$ & $-0.54[-1.23,0.15]$ & & \\
\hline Atig, et al. 2017 & 2.03 & 0.84 & 100 & 2.49 & 1.46 & 50 & $8.3 \%$ & $-0.42[-0.76,-0.08]$ & & \\
\hline Siciliano, et al. 2001 & 27.11 & 6.5 & 90 & 29 & 7 & 25 & $8.2 \%$ & $-0.28[-0.73,0.16]$ & & \\
\hline Micheli, et al. 2016 & 11.03 & 2.94 & 16 & 2.9 & 0.58 & 14 & $7.3 \%$ & $3.62[2.40,4.83]$ & & 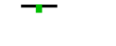 \\
\hline Total $(95 \% \mathrm{Cl})$ & & & 740 & & & 263 & $100.0 \%$ & $-1.91[-2.79,-1.04]$ & 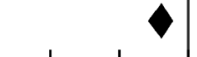 & \\
\hline $\begin{array}{l}\text { Heterogeneity: } \text { Tau }^{2}=2.37 \\
\text { Test for overall effect: } Z=4\end{array}$ & $\begin{array}{l}\mathrm{Chi}^{2}=2 \\
28(\mathrm{P}<\end{array}$ & $\begin{array}{l}80.39, d \\
0.0001)\end{array}$ & $f=12$ & $P<0.00$ & $001) ; 1^{2}=$ & $=96 \%$ & & & $\begin{array}{ccc}-10 & -5 & 0 \\
\text { Favours [Fertility] }\end{array}$ & $\begin{array}{c}5 \\
\text { Favours [ln }\end{array}$ \\
\hline
\end{tabular}

Figure 8: Meta-analysis of studies addressing catalase activity in seminal plasma of infertile patients and control subjects. Results are shown as standardized mean differences (SMDs).

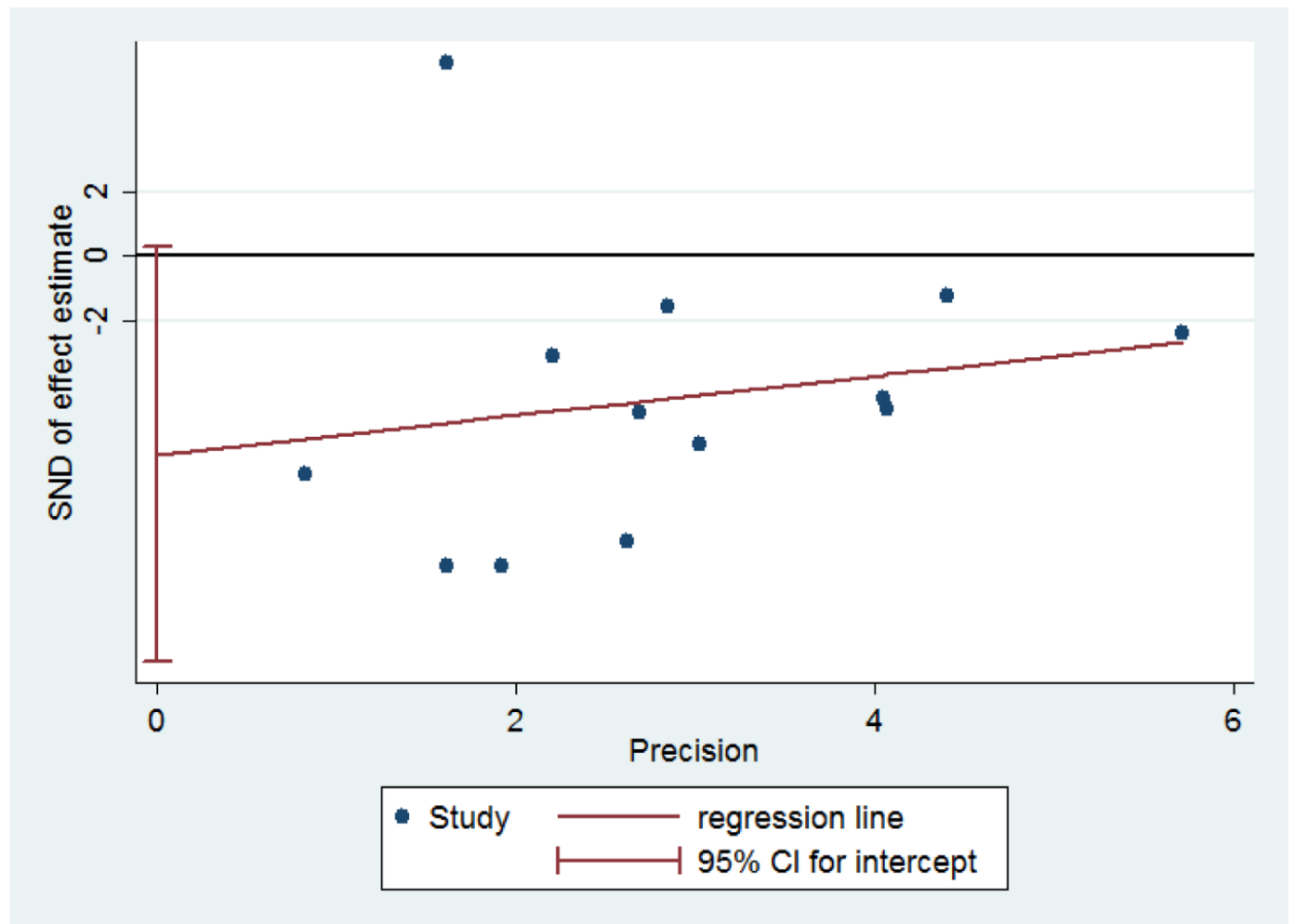

\begin{tabular}{r|rrrrrr} 
Number of studies $=13$ & & & Root MSE & 4.35 \\
\hline Std_Eff & Coef. & Std. Err. & $t$ & P>|t| & [95\% Conf. Interval] \\
\hline $\begin{array}{r}\text { slope } \\
\text { bias }\end{array}$ & -6.19329 & $\mathbf{6} .940102$ & -2.11 & 0.059 & -12.66441 & .2778316 \\
\hline
\end{tabular}

Figure 9: Evidence of publication bias in catalase activity was assessed using funnel plot asymmetry and Egger's regression. 


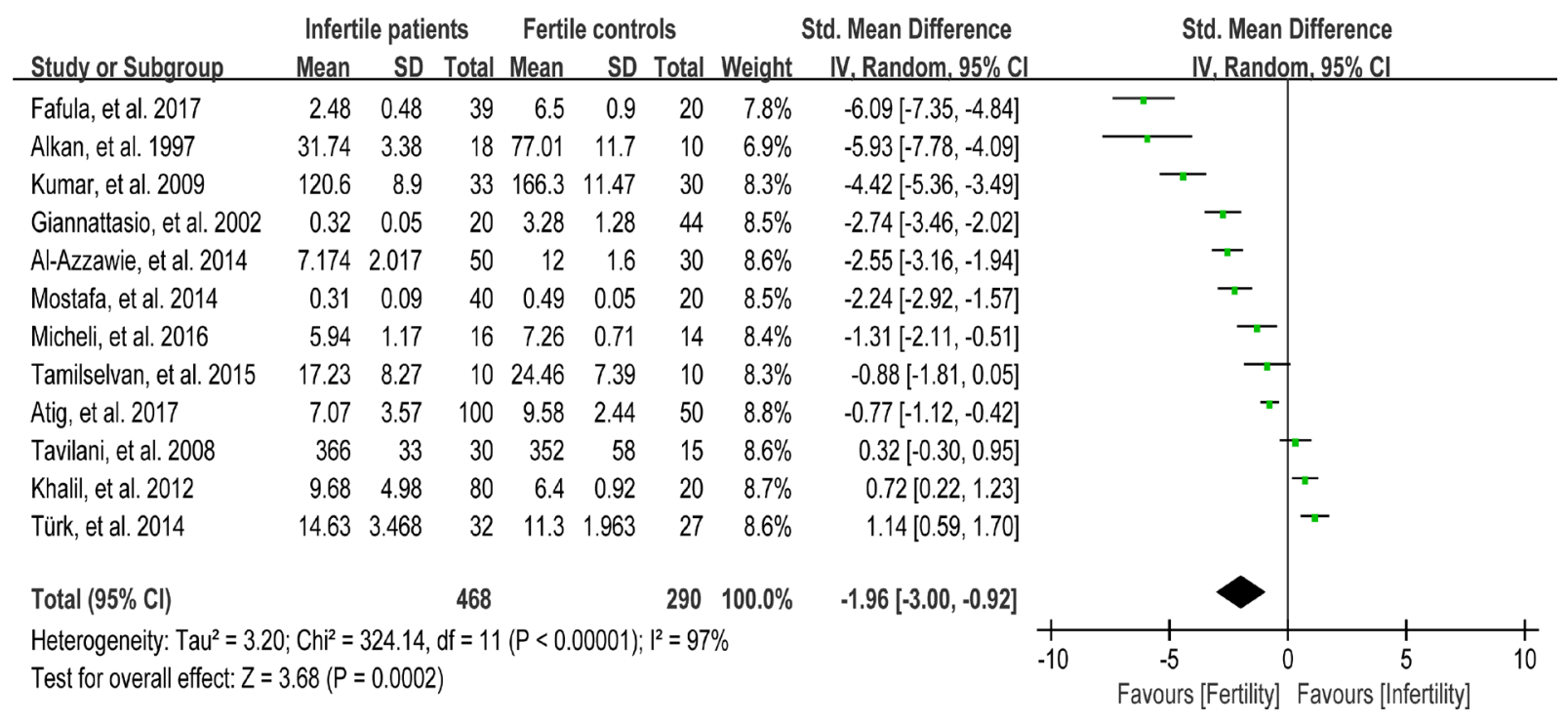

Figure 10: Meta-analysis of studies addressing GPX activity in seminal plasma of infertile patients and control subjects. Results are shown as standardized mean differences (SMDs).

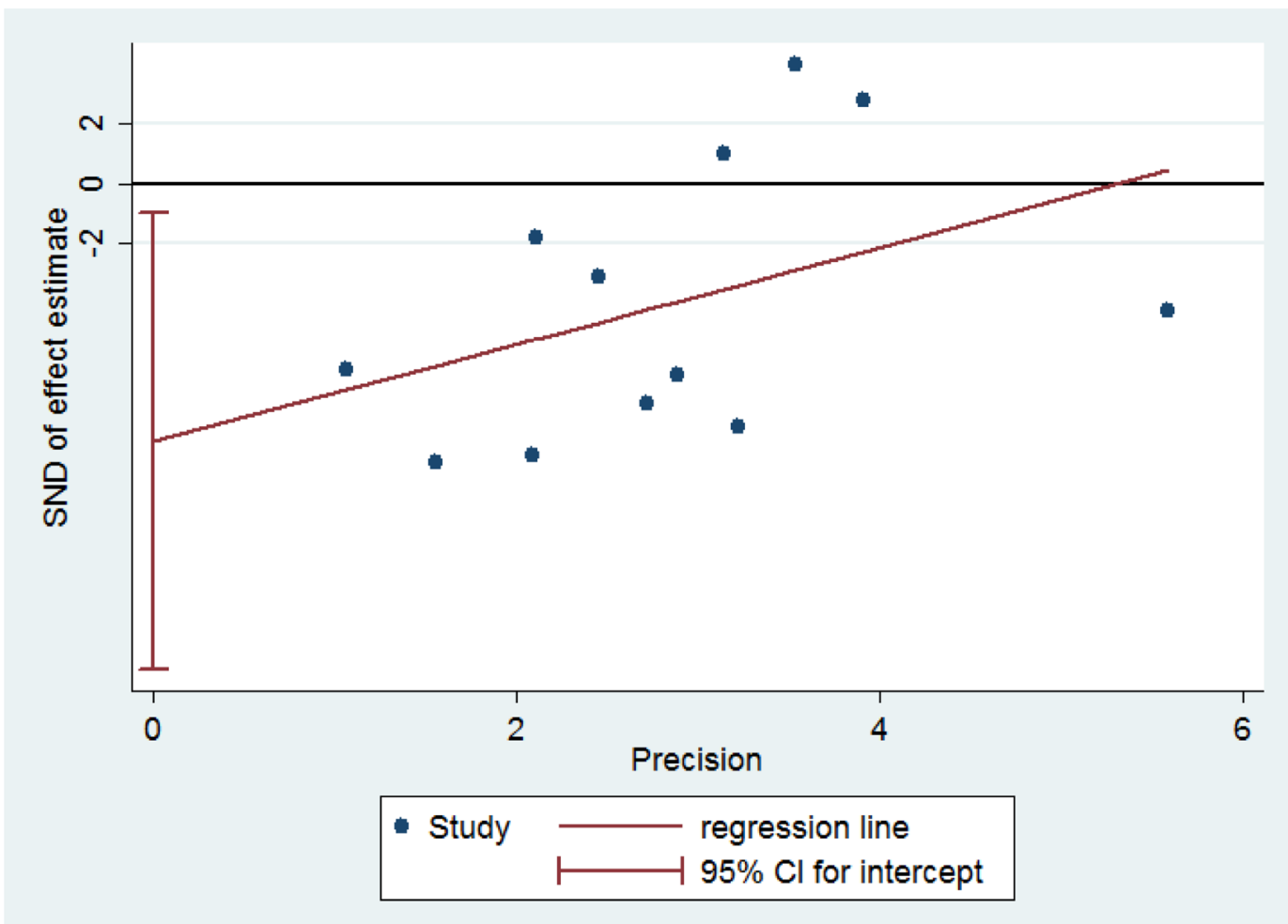

\begin{tabular}{|c|c|c|c|c|c|c|}
\hline Std_Eff & Coef. & Std. Err. & t & $P>|t|$ & [95\% Conf. & Interval] \\
\hline slope & 1.644096 & 1.131794 & 1.45 & 0.177 & -.8776977 & 4.16589 \\
\hline bias & -8.752643 & 3.479275 & -2.52 & 0.031 & -16.50495 & -1.000335 \\
\hline
\end{tabular}

Figure 11: Evidence of publication bias in GPX activity was assessed using funnel plot asymmetry and Egger's regression. 
present in semen. Semen antioxidant defenses include a network of compartmentalized antioxidant enzymic and nonenzymic molecules that are usually distributed within the spermatozoa and seminal plasma. In our meta-analysis, both enzymic antioxidants and non-enzymic antioxidants were evaluated. The results indicated that the activities of seminal enzymic antioxidants, such as catalase, GPX and GST, were remarkably decreased in infertility patients, and the concentrations of seminal non-enzymic antioxidants, such as GSH, VC and VE, were obviously lower in infertility patients. All of these changes resulted in a significantly lower total antioxidant capacity (TAC) in

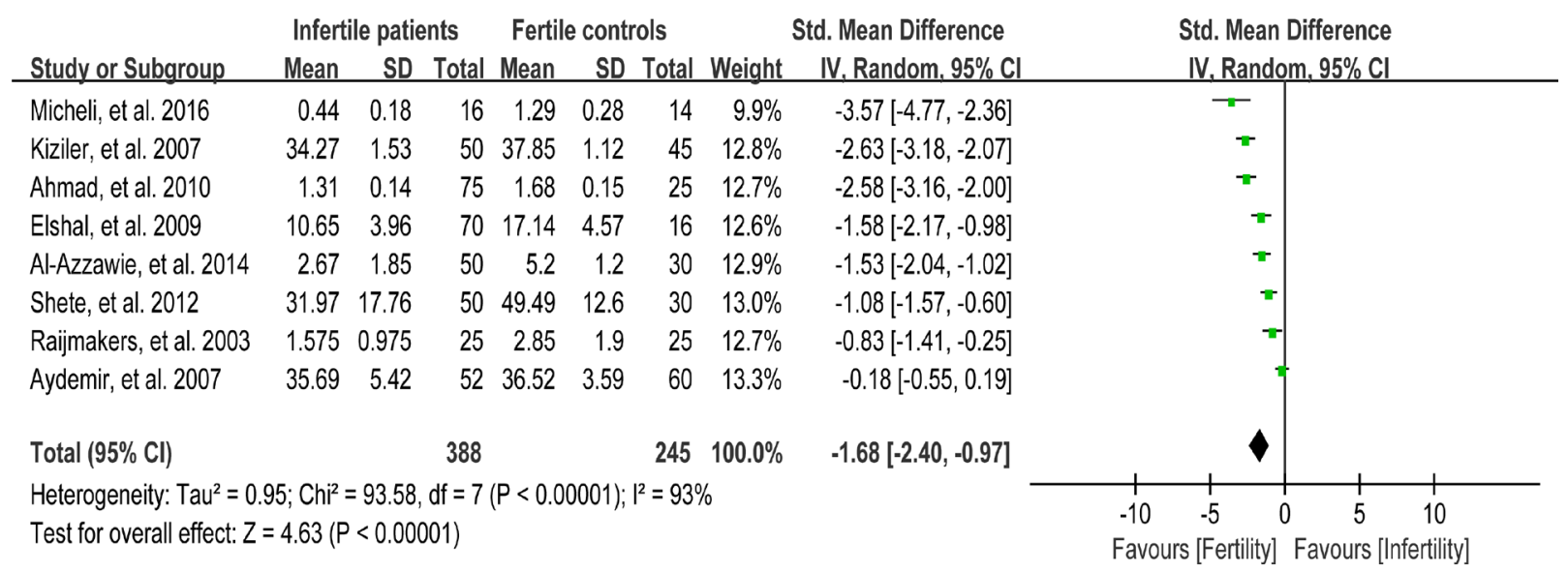

Figure 12: Meta-analysis of studies addressing reduced GSH concentration in seminal plasma of infertile patients and control subjects. Results are shown as g standardized mean differences (SMDs).

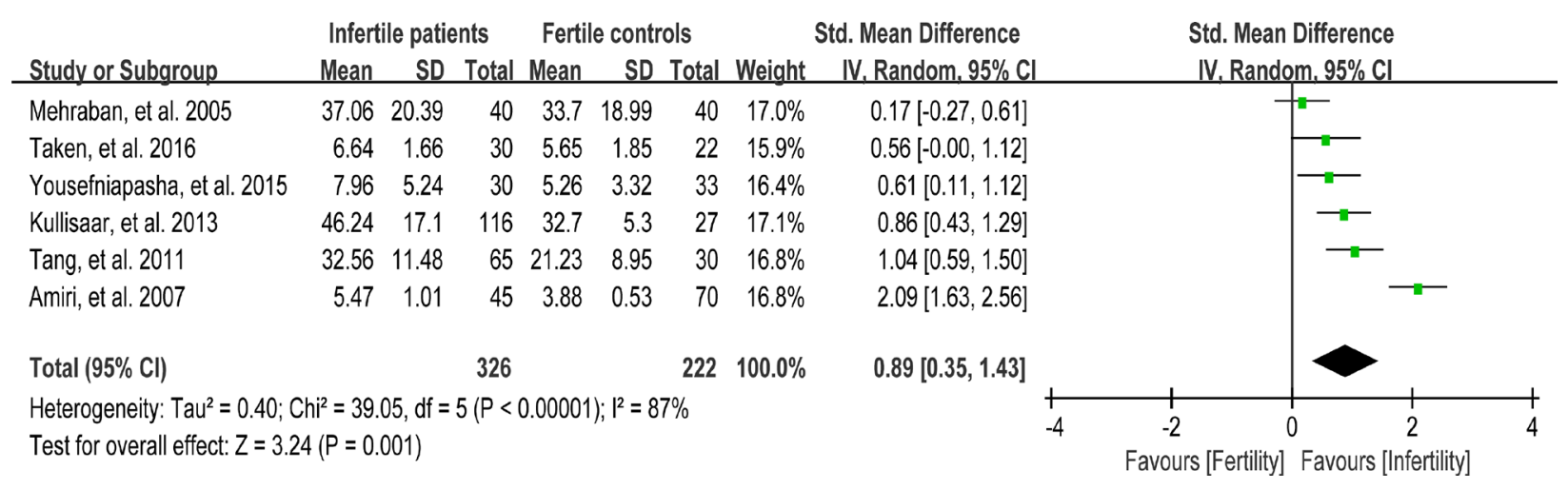

Figure 13: Meta-analysis of studies addressing NO concentration in seminal plasma of infertile patients and control subjects. Results are shown as standardized mean differences (SMDs).

\begin{tabular}{|c|c|c|c|c|c|c|c|c|c|c|c|c|}
\hline \multirow[b]{2}{*}{ Study or Subgroup } & \multicolumn{3}{|c|}{ Infertile patients } & \multicolumn{3}{|c|}{ Fertile controls } & \multicolumn{2}{|r|}{ Std. Mean Difference } & \multirow{2}{*}{\multicolumn{4}{|c|}{$\begin{array}{r}\text { Std. Mean Difference } \\
\text { IV. Random, } 95 \% \mathrm{Cl}\end{array}$}} \\
\hline & Mean & SD & Total & Mean & SD & Total & Weight & IV. Random, $95 \% \mathrm{Cl}$ & & & & \\
\hline Ahmad, et al. 2010 & 0.092 & 0.021 & 75 & 0.143 & 0.012 & 75 & $20.4 \%$ & $-2.97[-3.43,-2.50]$ & & - & & \\
\hline Al-Azzawie, et al. 2014 & 0.29 & 0.18 & 50 & 0.7 & 0.2 & 30 & $19.9 \%$ & $-2.16[-2.73,-1.60]$ & & - & & \\
\hline Nouri, et al. 2008 & 0.3 & 0.15 & 60 & 0.5 & 0.2 & 40 & $20.5 \%$ & $-1.16[-1.59,-0.72]$ & & - & & \\
\hline Benedetti, et al. 2012 & 1.46 & 0.3 & 31 & 1.68 & 0.25 & 12 & $19.3 \%$ & $-0.75[-1.44,-0.06]$ & & - & & \\
\hline Lewis, et al. 1997 & 0.42 & 0.07 & 41 & 0.44 & 0.05 & 18 & $20.0 \%$ & $-0.31[-0.86,0.25]$ & & & & \\
\hline Total $(95 \% \mathrm{Cl})$ & & & 257 & & & 175 & $100.0 \%$ & $-1.48[-2.45,-0.51]$ & & & & \\
\hline \multicolumn{9}{|c|}{ Heterogeneity: Tau $^{2}=1.15 ; \mathrm{Chi}^{2}=67.31, \mathrm{df}=4(\mathrm{P}<0.00001) ;\left.\right|^{2}=94 \%$} & -10 & -5 & 0 & 10 \\
\hline \multicolumn{9}{|c|}{ Test for overall effect: $Z=2.98(P=0.003)$} & & urs [Fertility] & Favours [ln & \\
\hline
\end{tabular}

Figure 14: Meta-analysis of studies addressing VE concentration in seminal plasma of infertile patients and control subjects. Results are shown as standardized mean differences (SMDs). 
infertile seminal plasma. SOD catalyzes the dismutation of the superoxide $\left(\mathrm{O}_{2}^{-}\right)$radical into either ordinary molecular oxygen $\left(\mathrm{O}_{2}\right)$ or hydrogen peroxide $\left(\mathrm{H}_{2} \mathrm{O}_{2}\right)$ [90]. Surprisingly, as an important antioxidant defense in nearly all living cells exposed to oxygen, it shows no statistically difference of activity in seminal plasma of infertility patients and fertility controls according to our meta-analysis. This result suggested that, compared with other antioxidants, the activity of SOD may vary greatly in different kinds of infertility, or more closely related to the severity of the infertility, so the SOD activity may not a suitable assay for infertility diagnosis. Coenzyme Q10 (CoQ10) appears to play an important role in energy metabolism, as well as function as a liposoluble chainbreaking antioxidant for cell membranes and lipoproteins [109]. The level of CoQ10 in seminal plasma was reported to be decreased in infertile patients [55], yet no differences were found between patients and controls in another study [41]. In general, the deficiencies of both enzymic antioxidants and non-enzymic antioxidants could be the exact causes of oxidative stress in the seminal plasma of infertility patients.

The strengths of our current systematic review and meta-analysis include the wide range of markers in oxidative stress evaluated, and the large number of subjects included. However, our study is not free of limitations.

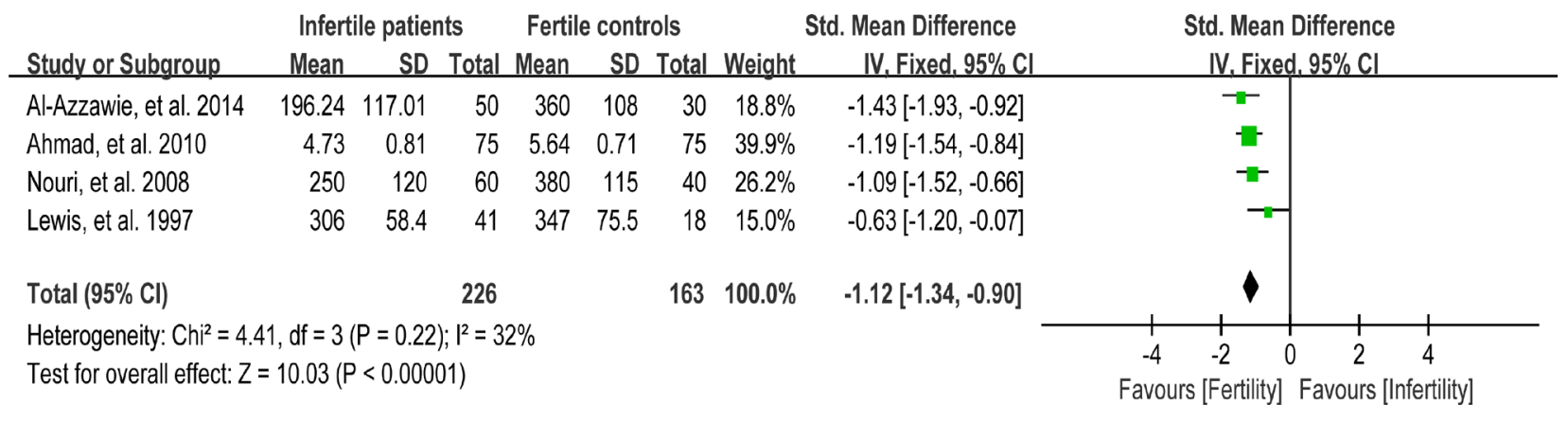

Figure 15: Meta-analysis of studies addressing VC concentration in seminal plasma of infertile patients and control subjects. Results are shown as standardized mean differences (SMDs).

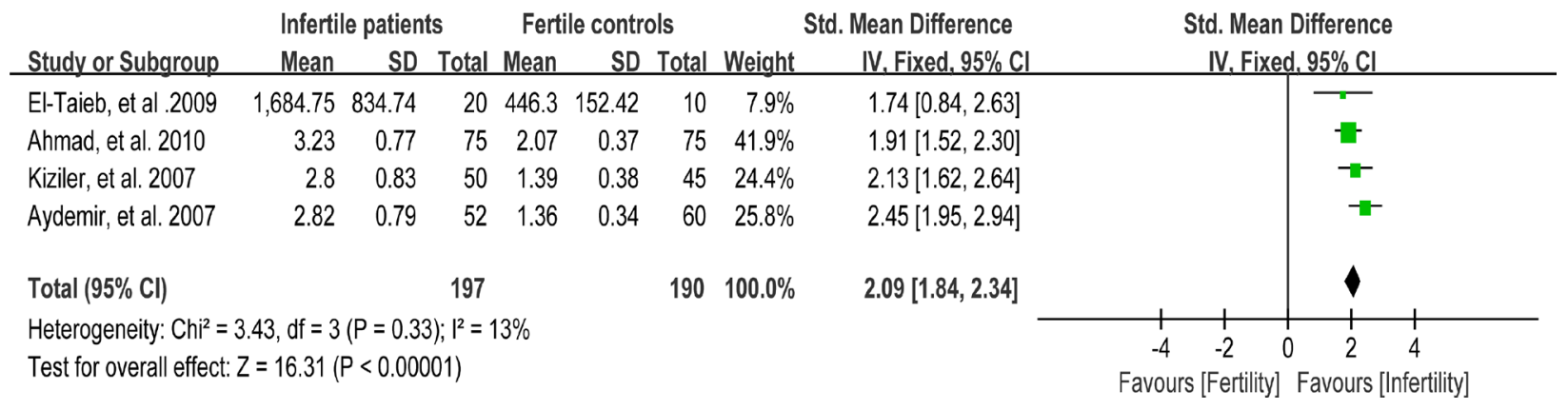

Figure 16: Meta-analysis of studies addressing carbonyl protein concentration in seminal plasma of infertile patients and control subjects. Results are shown as standardized mean differences (SMDs).

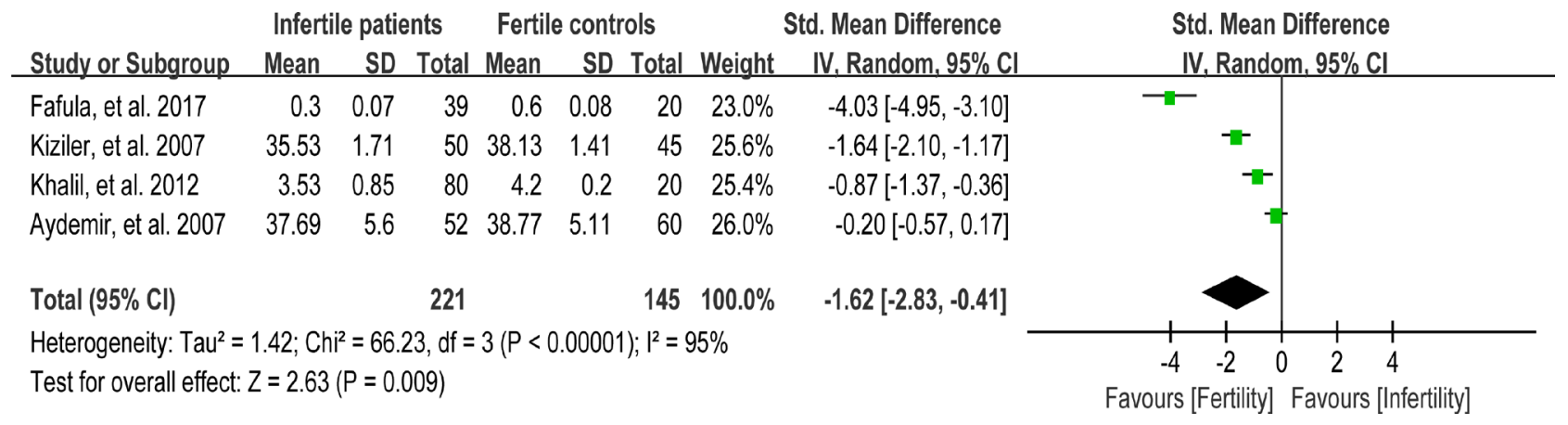

Figure 17: Meta-analysis of studies addressing GST activity in seminal plasma of infertile patients and control subjects. Results are shown as standardized mean differences (SMDs). 


\begin{tabular}{|c|c|c|}
\hline Marker & Action & $\begin{array}{l}\text { Changes in } \\
\text { male infertility }\end{array}$ \\
\hline MDA & By-product of lipid peroxidation & $\uparrow$ \\
\hline TAC & Prevents oxidation and detoxifies oxidants & $\downarrow$ \\
\hline SOD & Converts superoxide anions to hydrogen peroxide and molecular oxygen & $\leftrightarrow$ \\
\hline Catalase & Detoxifies both intracellular and extracellular $\mathrm{H} 2 \mathrm{O} 2$ to water and oxygen & $\downarrow$ \\
\hline GPX & $\begin{array}{l}\text { Reduce lipid hydroperoxides to their corresponding alcohols and to reduce free } \\
\text { hydrogen peroxide to water }\end{array}$ & $\downarrow$ \\
\hline GST & $\begin{array}{l}\text { Detoxify xenobiotics by catalyzing the nucleophilic attack by GSH on } \\
\text { electrophilic carbon }\end{array}$ & $\downarrow$ \\
\hline GSH & $\begin{array}{l}\text { Detoxifies hydrogen peroxide and lipid peroxides, prevents protein from } \\
\text { oxidation }\end{array}$ & $\downarrow$ \\
\hline NO & Promotes reactive nitrogen species & $\uparrow$ \\
\hline Carbonyl protein & Products of protein oxidation & $\uparrow$ \\
\hline $\mathrm{VC}$ & Neutralize hydroxyl, superoxide, and hydrogen peroxide radicals & $\downarrow$ \\
\hline VE & scavenge superoxide, $\mathrm{H}_{2} \mathrm{O}_{2}$, and hydroxyl radicals & $\downarrow$ \\
\hline
\end{tabular}

$\downarrow$, decreased; $\uparrow$, increased; $\leftrightarrow$, unchanged.

First, the heterogeneity among the studies of most analyzed markers (MDA, TAC, SOD, CAT, GPX, GSH, GST, VE) associated with infertility was modest $(>50 \%)$ and could not be reduced lower than $50 \%$ neither by reasonable exclusion nor subgroup analysis (Data not shown). Such heterogeneity may be related to the following factors: (1) search bias may be present when the inclusion of only English and Chinese articles and the exclusion of articles in other languages; (2) selection bias may be of evidence because no randomized controlled trial was performed in these studies and there were differences in the geographic areas and races of the study subjects, and there were also lack of definition for the review population; (3) measurement bias may occur from the differences in the reagent kits, testing equipment, and assay methods. Second, although the publication bias was evaluated in the markers with more than 10 studies, bias may still be present in the fewer than 10 articles reporting other markers. Such biases can be resolved by increasing the number of included articles in future research. Third, SMD analysis can be applied to data where different measurement scales are reported for the same outcome. However, the limitation of SMD analysis is often confined to $<10$ subjects per group and more conservative than normalized mean difference (NMD) [110]. Finally, the qualities of the pooled evidence were very low as assessed by the GRADE approach (Supplementary Table 1), thus the results must be interpreted with caution.

In conclusion, as summarized in Table 2, in light of the evidence available at present, our systematic review and meta-analysis indicates that several markers of oxidative stress are abnormal in seminal plasma of men with infertility, indicating these might be associated with male infertility, and more studies addressing these markers should be encouraged. Accordingly, this analysis might guide studies of certain interventions upon male infertility.

\section{ACKNOWLEDGMENTS}

This work was supported by the Key project of Sichuan Provincial Education Department National (16ZA0029 to C.H) and in part by grants from Natural Science Foundation of China (31501200 to C.H), and National Key Technology Support Program (2014BAI03B01 to Z.C).

\section{CONFLICTS OF INTEREST}

The authors declare no conflicts of interest.

\section{REFERENCES}

1. World Health Organization. WHO laboratory manual for the examination of human semen and sperm-cervical mucus interaction. Cambridge, United Kingdom: Cambridge University Press; 1999.

2. Hwang K, Walters RC, Lipshultz LI. Contemporary concepts in the evaluation and management of male infertility. Nat Rev Urol. 2011; 8:86-94.

3. Kupis Ł, Dobroński PA, Radziszewski P. Varicocele as a source of male infertility-current treatment techniques. Cent European J Urol. 2015; 68:365.

4. O'Brien KLF, Varghese AC, Agarwal A. The genetic causes of male factor infertility: a review. Fertil Steril. 2010; 93:1-12.

5. Greil AL. Infertility and psychological distress: a critical review of the literature. Soc Sci Med. 1997; 45:1679-1704. 
6. Zini A, Garrels K, Phang D. Antioxidant activity in the semen of fertile and infertile men. Urology. 2000; 55:922-926.

7. Agarwal A, Sharma RK, Nallella KP, Thomas AJ Jr, Alvarez JG, Sikka SC. Reactive oxygen species as an independent marker of male factor infertility. Fertil Steril. 2006; 86:878-885.

8. Khosrowbeygi A, Zarghami N. Levels of oxidative stress biomarkers in seminal plasma and their relationship with seminal parameters. BMC Clin Pathol. 2007; 7:6.

9. Aitken J, Fisher H. Reactive oxygen species generation and human spermatozoa: the balance of benefit and risk, Bioessays. 1994; 16:259-267.

10. Agarwal A, Prabakaran S, Allamaneni S. What an andrologist/urologist should know about free radicals and why. Urology. 2006; 67:2-8.

11. Lopes S, Jurisicova A, Sun JG, Casper RF. Reactive oxygen species: potential cause for DNA fragmentation in human spermatozoa. Hum Reprod. 1998; 13:896-900.

12. Kao SH, Chao HT, Chen HW, Hwang TI, Liao TL, Wei YH. Increase of oxidative stress in human sperm with lower motility. Fertil Steril. 2008; 89:1183-1190.

13. Mostafa T, Rashed LA, Osman I, Marawan M. Seminal plasma oxytocin and oxidative stress levels in infertile men with varicocele. Andrologia. 2015; 47:209-213.

14. Agarwal A, Saleh RA, Bedaiwy MA. Role of reactive oxygen species in the pathophysiology of human reproduction. Fertil Steril. 2003; 79:829-843.

15. Tremellen K. Oxidative stress and male infertility--a clinical perspective. Hum Reprod. 2008; 14:243-258.

16. Shiva M, Gautam AK, Verma Y, Shivgotra V, Doshi H, Kumar S. Association between sperm quality, oxidative stress, and seminal antioxidant activity. Clin Biochem. 2011; 44:319-324.

17. Bansal AK, Bilaspuri GS. Impacts of oxidative stress and antioxidants on semen functions. Vet Med Int. 2010.

18. Aitken RJ, Baker MA. Oxidative stress, sperm survival and fertility control. Mol Cell Enocrinol. 2006; 250:66-69.

19. Venkatesh S, Shamsi MB, Deka D, Saxena V, Kumar R, Dada R. Clinical implications of oxidative stress \& sperm DNA damage in normozoospermic infertile men. Ind J Med Res. 2011; 134:396-398.

20. Hozo SP, Djulbegovic B, Hozo I. Estimating the mean and variance from the median, range, and the size of a sample. BMC Med Res Methodol. 2005; 5:13.

21. Borenstein M, Hedges LV, Higgins J, Rothstein HR. Introduction to meta-analysis. Wiley Online Library, UK, 2009.

22. Wells G, Shea BD, O'Connell R, Peterson J, Welch V, Losos M, Tugwell P. The Newcastle-Ottawa Scale (NOS) for assessing the quality of nonrandomised studies in metaanalyses. Ottawa: Ottawa Hospital Research Institute; 2014, oxford. asp, 2014.
23. Atkins D, Best D, Briss PA, Eccles M, Falck-Ytter Y, Flottorp S, Guyatt GH, Harbour RT, Haugh MC, Henry D, Hill S, Jaeschke R, Leng G, et al. Grading quality of evidence and strength of recommendations. BMJ. 2004; 328:1490.

24. Egger M, Smith GD, Schneider M, Minder C. Bias in metaanalysis detected by a simple, graphical test. BMJ. 1997; 315:629-634.

25. Copas J, Shi JQ. Meta-analysis, funnel plots and sensitivity analysis. Biostatistics. 2000; 1:247-262.

26. Atig F, Kerkeni A, Saad A, Ajina M. Effects of reduced seminal enzymatic antioxidants on sperm DNA fragmentation and semen quality of Tunisian infertile men. J Assist Reprod Genet. 2017; 34:373-381.

27. Fafula DV, Onufrovych OK, Vorobets DZ, Iefremova UP, Vorobets ZD. Glutathione antioxidant protection system in ejaculated spermatozoa of infertile men with different forms of pathospermia. Studia Biologica. 2017; 11:17-24.

28. Vatannejad A, Tavilani H, Sadeghi MR, Amanpour S, Shapourizadeh S, Doosti M. Evaluation of ROS-TAC Score and DNA Damage in Fertile Normozoospermic and Infertile Asthenozoospermic Males, Urol J. 2017; 14:2973.

29. Fazeli F, Salimi S. Correlation of seminal plasma total antioxidant capacity and malondialdehyde levels with sperm parameters in men with idiopathic infertility. Avicenna J Med Biochem. 2016; 4.

30. Micheli L, Cerretani D, Collodel G, Menchiari A, Moltoni L, Fiaschi AI, Moretti E. Evaluation of enzymatic and non-enzymatic antioxidants in seminal plasma of men with genitourinary infections, varicocele and idiopathic infertility. Andrology. 2016; 4:456-464.

31. Riaz M, Mahmood Z, Shahid M, Saeed MU, Tahir IM, Shah SA, Munir NA. El-Ghorab, Impact of reactive oxygen species on antioxidant capacity of male reproductive system. Int J Immunopathol Pharmacol. 2016; 29:421-425.

32. Roychoudhury S, Sharma R, Sikka S, Agarwal A. Diagnostic application of total antioxidant capacity in seminal plasma to assess oxidative stress in male factor infertility. J Assist Reprod Genet. 2016; 33:627-635.

33. Taken K, Alp HH, Eryilmaz R, Donmez MI, Demir M, Gunes M, Aslan R, Sekeroglu MR. Oxidative DNA Damage to Sperm Cells and Peripheral Blood Leukocytes in Infertile Men. Med Sci Mon. 2016; 22:4289-4296.

34. El-Taieb MA, Ali MA, Nada EA. Oxidative stress and acrosomal morphology: A cause of infertility in patients with normal semen parameters. Mid East Fertil Soc J. 2015; 20:79-85.

35. Layali I, Tahmasbpour E, Joulaei M, Jorsaraei SG, Farzanegi P. Total antioxidant capacity and lipid peroxidation in semen of patient with hyperviscosity. Cell journal. 2015; 16:554-559.

36. Tamilselvan K, Ravinder SS, Thangavel G, Subashini A, Padmavathi R. A study of variation in the levels of seminal plasma superoxide dismutase and glutathione peroxidase 
in normospermic and oligozoospermic men. International Journal of Biomedical Research. 2015; 6:263-267.

37. Yousefniapasha Y, Jorsaraei G, Gholinezhadchari M, Mahjoub S, Hajiahmadi M, Farsi M. Nitric oxide levels and total antioxidant capacity in the seminal plasma of infertile smoking men. Cell journal. 2015; 17:129-136.

38. Zhao Y, Zhao E, Zhang C, Zhang H. Study of the Changes of Acrosomal Enzyme, Nitric Oxide Synthase, and Superoxide Dismutase of Infertile Patients with Positive Antisperm Antibody in Seminal Plasma. Cell biochemistry and biophysics. 2015; 73:639-642.

39. Al-Azzawie HF, Naeim M, Saleman ED. Evaluation of enzymatic and non-enzymatic antioxidant status in seminal plasma of Iraqi Infertile Men. International Journal. 2014; 2:158-167.

40. Collodel G, Moretti E, Micheli L, Menchiari A, Moltoni L, Cerretani D. Semen characteristics and malondialdehyde levels in men with different reproductive problems. Andrology. 2015; 3:280-286.

41. Eroglu M, Sahin S, Durukan B, Ozakpinar OB, Erdinc N, Turkgeldi L, Sofuoglu K, Karateke A. Blood Serum and Seminal Plasma Selenium, Total Antioxidant Capacity and Coenzyme Q10 Levels in Relation to Semen Parameters in Men with Idiopathic Infertility. Biological trace element research. 2014; 159:46-51.

42. Turk S, Mandar R, Mahlapuu R, Viitak A, Punab M, Kullisaar T. Male infertility: decreased levels of selenium, zinc and antioxidants, Journal of trace elements in medicine and biology : organ of the Society for Minerals and Trace Elements. 2014; 28:179-185.

43. Jiao R, Feng H, Tang J, Fang J, Feng J, Zhan S, Zhou P, Chen R. Influence of seminal oxidative stress on sperm DNA integrity and other parameters in males with infertility. Laboratory Medicine. 2013; 28:487-491.

44. Kullisaar T, Turk S, Kilk K, Ausmees K, Punab M, Mandar R. Increased levels of hydrogen peroxide and nitric oxide in male partners of infertile couples. Andrology. 2013; $1: 850-858$.

45. Mehrotra A, Katiyar DK, Agarwal A, Das V, Pant KK. Role of total antioxidant capacity and lipid peroxidation in fertile and infertile men. Biomed Res-India. 2013; 24:347-352.

46. Benedetti S, Tagliamonte MC, Catalani S, Primiterra M, Canestrari FS. Stefani D, Palini S, Bulletti C. Differences in blood and semen oxidative status in fertile and infertile men, and their relationship with sperm quality. Reproductive biomedicine online. 2012; 25:300-306.

47. Gao Y, Gao Y, Du L, Qin Z, Hu Z. [Zinc, lead, cadmium, malondialdehyde contents and superoxide dismutase activity in serum and seminal plasma in male infertility patients]. [Article in Chinese]. J Reprod Med. 2012; 21:43-46.

48. Sarhan E. Oxidative stress induces idiopathic infertility in Egyptian males. Afr J Biotechnol. 2011;11:1516-1522.

49. Shamsi MB, Kumar R, Malhotra N, Singh N, Mittal S, Upadhyay AD, Dada R. Chromosomal aberrations,
Yq microdeletion, and sperm DNA fragmentation in infertile men opting for assisted reproduction. Molecular reproduction and development. 2012; 79:637-650.

50. Shrikant AS, Thakare A, Patil P. Study of reduced glutathione in seminal plasma and spermatozoa nuclear chromatin decondensation test (NCDT) in human subjects with different fertility potential. Int J Biol Med Res. 2012; 2.

51. You YQ, Gong DY, Zi-Ping LI, Kang M, Zhuang XW. The clinical value of determination of reactive oxygen species and seminal plasma malondialdehyde in male sterility patients semen. Laboratory Medicine \& Clinic. 2012.

52. Badade Z, More K, Narshetty J. Oxidative stress adversely affects spermatogenesis in male infertility. Biomedical Research. 2011; 22.

53. Zhong-Pei L, Deng W, Ai-Lian YU, Wang F, Dong-Ming Z. Relationship between levels of reactive oxygen species and cytokines in sterile men. Journal of Pathogen Biology. 2011; 6:486-489.

54. Tang K, Xue W, Xing Y, Xu S, Wu Q, Liu R, Wang X, Xing J. Genetic Polymorphisms of Glutathione S-Transferase M1, $\mathrm{T} 1$, and P1, and the Assessment of Oxidative Damage in Infertile Men With Varicoceles From Northwestern China. Journal of andrology. 2012; 33:257-263.

55. Abdulrasheed OF, Farid YY, Alnasiri US. Coenzyme Q10 and oxidative stress markers in seminal plasma of Iraqi patients with male infertility. Saudi medical journal. 2010; 31:501.

56. Ahmad MK, Mahdi AA, Shukla KK, Islam N, Rajender S, Madhukar D, Shankhwar SN, Ahmad S. Withania somnifera improves semen quality by regulating reproductive hormone levels and oxidative stress in seminal plasma of infertile males. Fertility and sterility. 2010; 94:989-996.

57. Ben Abdallah F, Dammak I, Attia H, Hentati B, AmmarKeskes L. Lipid peroxidation and antioxidant enzyme activities in infertile men: correlation with semen parameter. Journal of clinical laboratory analysis. 2009; 23:99-104.

58. Elshal MF, El-Sayed IH, Elsaied MA, El-Masry SA, Kumosani TA. Sperm head defects and disturbances in spermatozoal chromatin and DNA integrities in idiopathic infertile subjects: association with cigarette smoking. Clinical biochemistry. 2009; 42:589-594.

59. El-Taieb MA, Herwig R, Nada EA, Greilberger J, Marberger M. Oxidative stress and epididymal sperm transport, motility and morphological defects. European journal of obstetrics, gynecology, and reproductive biology. 2009; 144:S199-203.

60. Kumar R, Venkatesh S, Kumar M, Tanwar M, Shasmsi MB, Kumar R, Gupta NP, Sharma RK, Talwar P, Dada R. Oxidative stress and sperm mitochondrial DNA mutation in idiopathic oligoasthenozoospermic men. Indian journal of biochemistry \& biophysics. 2009; 46:172-177.

61. Mahfouz R, Sharma R, Sharma D, Sabanegh E, Agarwal A. Diagnostic value of the total antioxidant capacity (TAC) in human seminal plasma. Fertility and sterility. 2009; 91:805-811. 
62. Mohammad N, Aliyeh G, Laya F, Vahideh S, Novin MG. Vitamins C, E and lipid peroxidation levels in sperm and seminal plasma of asthenoteratozoospermic and normozoospermic men. 2008; 6:1-5.

63. Tavilani H, Goodarzi MT, Vaisi-Raygani A, Salimi S, Hassanzadeh T. Activity of antioxidant enzymes in seminal plasma and their relationship with lipid peroxidation of spermatozoa. International braz j urol. 2008; 34:485-491.

64. Amiri I, Sheikh N, Najafi R. Nitric oxide level in seminal plasma and its relation with sperm DNA damages, Iranian biomedical journal. 2007; 11:259-264.

65. Aydemir B, Onaran I, Kiziler AR, Alici B, Akyolcu MC. Increased oxidative damage of sperm and seminal plasma in men with idiopathic infertility is higher in patients with glutathione S-transferase Mu-1 null genotype. Asian journal of andrology. 2007; 9:108-115.

66. Kiziler AR, Aydemir B, Onaran I, Alici B, Ozkara H, Gulyasar T, Akyolcu MC. High levels of cadmium and lead in seminal fluid and blood of smoking men are associated with high oxidative stress and damage in infertile subjects, Biological trace element research. 2007; 120:82-91.

67. Murawski M, Saczko J, Marcinkowska A, Chwilkowska A, Grybos M, Banas T. Evaluation of superoxide dismutase activity and its impact on semen quality parameters of infertile men. Folia histochemica et cytobiologica. 2007; 45:S123-126.

68. Verit FF, Verit A, Kocyigit A, Ciftci H, Celik H, Koksal M. No increase in sperm DNA damage and seminal oxidative stress in patients with idiopathic infertility. Archives of Gynecology \& Obstetrics. 2006; 274:339.

69. Mehraban D, Ansari M, Keyhan H, Sedighi Gilani M, Naderi G, Esfehani F. Comparison of nitric oxide concentration in seminal fluid between infertile patients with and without varicocele and normal fertile men. Urology journal. 2005; 2:106-110.

70. Shi YC, Sun HM, Shang XJ, Zhu PY, Huang YF. [Total antioxidant capacity of seminal plasma in fertile and infertile men] Article in Chinese. Nationlal Journal of Andrology. 2005; 11:915-917.

71. Tavilani H, Doosti M, Saeidi H. Malondialdehyde levels in sperm and seminal plasma of asthenozoospermic and its relationship with semen parameters. Clinica chimica acta; international journal of clinical chemistry. 2005; 356:199-203.

72. Li K, Shang X, Chen Y. High-performance liquid chromatographic detection of lipid peroxidation in human seminal plasma and its application to male infertility. Clinica chimica acta; international journal of clinical chemistry. 2004; 346:199-203.

73. Koca Y, Ozdal OL, Celik M, Unal S, Balaban N. Antioxidant activity of seminal plasma in fertile and infertile men. Archives of andrology. 2003; 49:355-359.

74. Raijmakers MT, Roelofs HM, Steegers EA, SteegersTheunissen RR, Mulder TP, Knapen MF, Wong WY, Peters WH. Glutathione and glutathione S-transferases A1-1 and
P1-1 in seminal plasma may play a role in protecting against oxidative damage to spermatozoa. Fertility and sterility. 2003; 79:169-172.

75. Giannattasio A, Rosa MD, Smeraglia R, Zarrilli S, Cimmino A, Rosario BD, Ruggiero R, Colao A, Lombardi G. Glutathione peroxidase (GPX) activity in seminal plasma of healthy and infertile males. Journal of endocrinological investigation. 2002; 25:983-986.

76. Siciliano L, Tarantino P, Longobardi F, Rago V, Stefano DC, Carpino A. Impaired seminal antioxidant capacity in human semen with hyperviscosity or oligoasthenozoospermia. Journal of andrology. 2001; 22:798-803.

77. Pasqualotto FF, Sharma RK, Kobayashi H, Nelson DR, Thomas AJ Jr, Agarwal A. Oxidative stress in normospermic men undergoing infertility evaluation. Journal of andrology. 2001; 22:316-322.

78. Sharma RK, Pasqualotto FF, Nelson DR, Thomas AJ Jr, Agarwal A. The reactive oxygen species-total antioxidant capacity score is a new measure of oxidative stress to predict male infertility. Human reproduction. 1999; 14:2801-2807.

79. Zhang J, Zhang L, Meng Q. Signification and detection on content of $\mathrm{Zn}, \mathrm{Cu}$ and superoxide dismutase in seminal plasma of Infertile men. Chinese Journal of Andrology. 1999.

80. Alkan I, Simsek F, Haklar G, Kervancioglu E, Ozveri H, Yalcin S, Akdas A. Reactive oxygen species production by the spermatozoa of patients with idiopathic infertility: relationship to seminal plasma antioxidants, The Journal of urology. 1997; 157:140-143.

81. Lewis SE, Sterling ES, Young IS, Thompson W. Comparison of individual antioxidants of sperm and seminal plasma in fertile and infertile men, Fertility and sterility. 1997; 67:142-147.

82. Kurpisz M, Miesel R, Sanocka D, Jedrzejczak P. Seminal plasma can be a predictive factor for male infertility, Human reproduction. 1996; 11:1223-1226.

83. Smith R, Vantman D, Ponce J, Escobar J, Lissi E. Total antioxidant capacity of human seminal plasma. Human reproduction. 1996; 11:1655-1660.

84. Fan ZML, Li X. [Determination of Superoxide Dismutase Activity in Seminal Plasma of Infertile Patients] Article in Chinese. Journal of Henan medical university. 1995; 373-375.

85. Chen Guo Qian LYS. Superoxide dismutase activity in semen of fertile and infertile men. Chinese Journal of Vrology, 49. 1994.

86. Jeulin C, Soufir JC, Weber P, Laval-Martin D, Calvayrac R. Catalase activity in human spermatozoa and seminal plasma. Gamete research. 1989; 24:185-196.

87. Li WN, Chen HL, Lin Y. Study on seminal plasma superoxide dismutase, zinc and testosterone in infertle men. Chinese Journal of Andrology. 1989.

88. Aitken RJ, Clarkson JS, Fishel S. Generation of reactive oxygen species, lipid peroxidation, and human sperm function. Biology of reproduction. 1989; 41:183-197. 
89. Khosravi F, Valojerdi MR, Amanlou M, Karimian L, Abolhassani F. Relationship of seminal reactive nitrogen and oxygen species and total antioxidant capacity with sperm DNA fragmentation in infertile couples with normal and abnormal sperm parameters. Andrologia. 2014; 46:17-23.

90. Fukai T, Ushio-Fukai M. Superoxide dismutases: role in redox signaling, vascular function, and diseases. Antioxidants \& redox signaling. 2011; 15:1583-1606.

91. Aebi H. [13] Catalase in vitro, Methods in enzymology. 1984; 105:121-126.

92. De Lamirande E, Leclerc P, Gagnon C. Capacitation as a regulatory event that primes spermatozoa for the acrosome reaction and fertilization. Molecular human reproduction. 1997; 3:175-194.

93. Bhabak KP, Mugesh G. Functional mimics of glutathione peroxidase: bioinspired synthetic antioxidants. Accounts of chemical research. 2010; 43:1408-1419.

94. Eskiocak S, Gozen AS, Yapar SB, Tavas F, Kilic AS, Eskiocak M. Glutathione and free sulphydryl content of seminal plasma in healthy medical students during and after exam stress. Human reproduction. 2005; 20:2595-2600.

95. Weinberg JB, Doty E, Bonaventura J, Haney AF. Nitric oxide inhibition of human sperm motility. Fertility and sterility. 1995; 64:408-413.

96. Agarwal A, Nallella KP, Allamaneni SS, Said TM. Role of antioxidants in treatment of male infertility: an overview of the literature. Reproductive biomedicine online. 2004; 8:616-627.

97. Berlett BS, Stadtman ER. Protein oxidation in aging, disease, and oxidative stress. The Journal of biological chemistry. 1997; 272:20313-20316.

98. Chevion M, Berenshtein E, Stadtman E. Human studies related to protein oxidation: protein carbonyl content as a marker of damage. Free radical research. 2000; 33:S99-108.

99. Hayes JD, Flanagan JU, Jowsey IR. Glutathione transferases. Annu. Rev. Pharmacol. Toxicol. 2005; 45:51-88.

100. Ross C, Morriss A, Khairy M, Khalaf Y, Braude P, Coomarasamy A, El-Toukhy T. A systematic review of the effect of oral antioxidants on male infertility. Reproductive biomedicine online. 2010; 20:711-723.

101. Agarwal A, Sharma RK, Nallella KP, Thomas AJ, Alvarez JG, Sikka SC. Reactive oxygen species as an independent marker of male factor infertility. Fertility and sterility. 2006; 86:878-885.

102. Fingerova H, Oborna I, Novotny J, Svobodova M, Brezinova J, Radova L. The measurement of reactive oxygen species in human neat semen and in suspended spermatozoa: a comparison, Reproductive biology and endocrinology : RB\&E. 2009; 7:118.

103. Desai N, Sharma R, Makker K, Sabanegh E, Agarwal A. Physiologic and pathologic levels of reactive oxygen species in neat semen of infertile men. Fertility and sterility. 2009; 92:1626-1631.

104. Venkatesh S, Riyaz AM, Shamsi MB, Kumar R, Gupta NP, Mittal S, Malhotra N, Sharma RK, Agarwal A, Dada R. Clinical significance of reactive oxygen species in semen of infertile Indian men. Andrologia. 2009; 41:251-256.

105. Wang X, Sharma RK, Sikka SC, Thomas AJ Jr, Falcone T, Agarwal A. Oxidative stress is associated with increased apoptosis leading to spermatozoa DNA damage in patients with male factor infertility. Fertility and sterility. 2003; 80:531-535.

106. Birben E, Sahiner UM, Sackesen C, Erzurum S, Kalayci O. Oxidative stress and antioxidant defense. World Allergy Organization Journal. 2012; 5:9.

107. Vatannejad A, Tavilani H, Sadeghi MR, Amanpour S, Shapourizadeh S, Doosti M. Evaluation of ROS-TAC Score and DNA Damage in Fertile Normozoospermic and Infertile Asthenozoospermic Males. Urology journal. 2017; 14:2973-2978.

108. Khosrowbeygi A, Zarghami N. Seminal plasma levels of free 8-isoprostane and its relationship with sperm quality parameters. Indian journal of clinical biochemistry: IJCB. 2008; 23:49-52.

109. Showell MG, Brown J, Yazdani A, Stankiewicz MT, Hart RJ. Antioxidants for male subfertility. The Cochrane database of systematic reviews. 2011; CD007411.

110. Vesterinen HM, Sena ES, Egan KJ, Hirst TC, Churolov L, Currie GL, Antonic A, Howells DW, Macleod MR. Metaanalysis of data from animal studies: a practical guide. Journal of neuroscience methods. 2014; 221:92-102. 